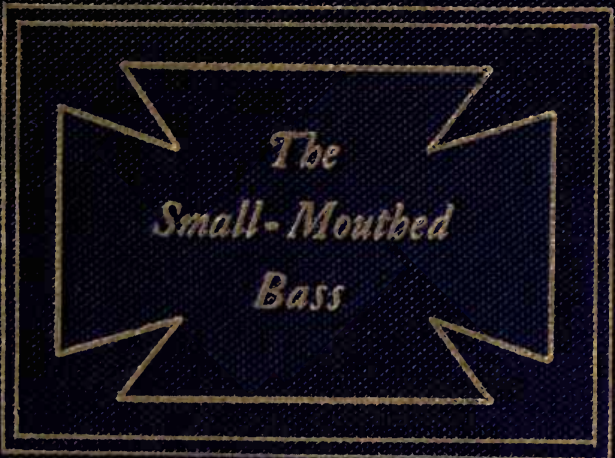





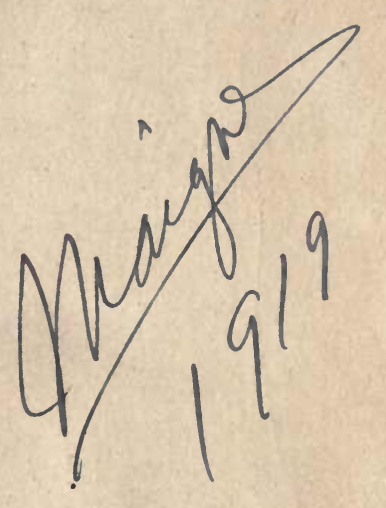







\section{THE SMALL-MOUTHED BASS}






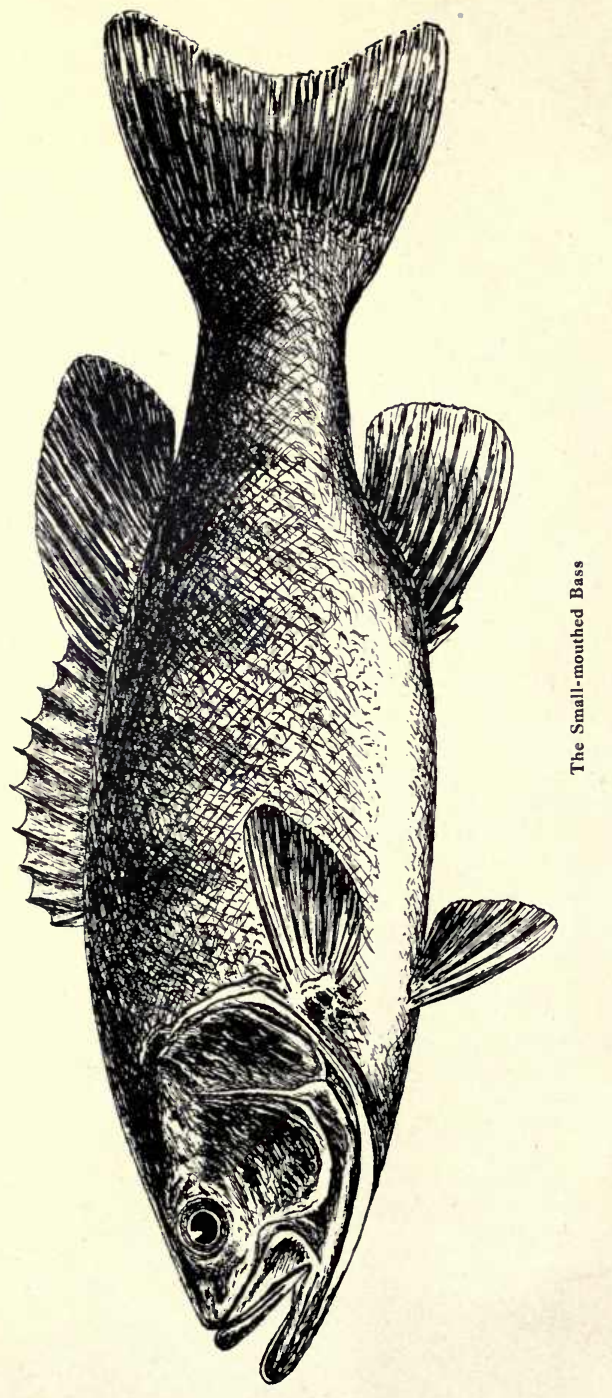


THE

\title{
Small-Mouthed Bass
}

\author{
BY \\ W. J. LOUDON \\ Professor of Mechanics in the University of Toronto
}

TORONTO:

THE HUNTER-ROSE CO., Limited

1910 
CopyrrGarted, CANADA, 1910
By W. J. LOUDON 


\section{PREFACE}

This book is not strictly a record of scientific investigation; being based upon a collection of observations made by myself, during the past ten summers, on the habits of the small-mouthed bass.

These observations have been condensed into their present form, not only for my own pleasure, but also for the benefit of all those who, while they may prefer to dwell in cities and to live under slated roofs, still long occasionally for a glimpse of forest trees, tumbling water, bare rock, and the open sky.

Although I am indebted to various scientific treatises on trees, plants and fishes, for valuable suggestions, yet the illustrations are, with few exceptions, original, and have been sketched either from photographs, or from natural objects.

\section{W. J. LOUDON}

September 22, 1910 



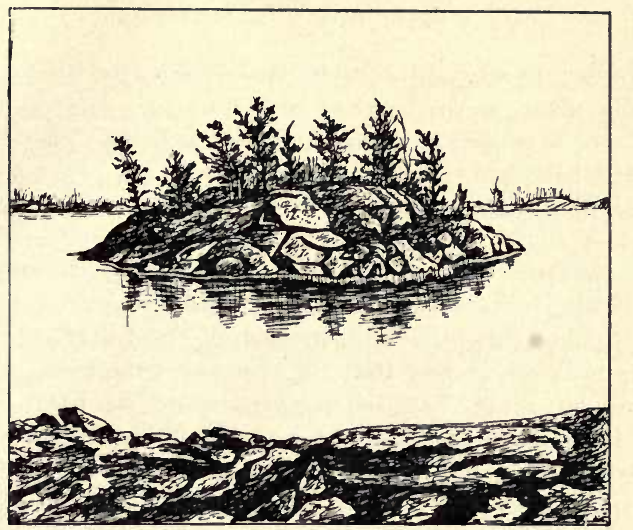

Lonely Island, Georgian Bay

\section{The Small-Mouthed Bass}

\section{CHAPTER I.}

\section{Gégraphical Distribution.}

ATHOUGH the small-mouthed bass is essentially A a product of the Great Lakes of Canada, yet, during the past century, it has been introduced artificially into so many parts of North America, and so few records have been kept of its distribution, that it is difficult now to trace its genealogy, except to a very limited extent.

Frank Forrester (1849), in a book entitled Fish and Fishing, says that this fish is peculiar to the basin of the Saint Lawrence and the Great Lakes, and found its way into the Hudson River through the Erie canal; he makes no mention of its having been taken anywhere in the United 
States, but refers to others who said that it had been caught in some places in the State of New York.

There is evidence, also, that in $1854, W . W$. Shriver put the first bass into the Potomac; and that there were no bass in the State of New York prior to the opening of the Erie Canal in 1825.

If we probe still further back into the past, we find that the Jesuit missionaries first used, in 1655 , the word achigan to designate this fish; and, in view of the fact that this is of Ojibway origin, and that the Ojibway tribe were, at that period, inhabitants of the northern shores of Lake Huron and Lake Superior, it seems probable that the bass were natives of these waters.

It may be noted here that the word achigan is still used in its original sense by the French-Canadians; it corresponds exactly to the French word bas, meaning a stocking. Whether or not it was applied to the bass by the Ojibways, from any similarity of form, or of pronunciation, is an interesting question for philologists.

It is to be noted, also, that Claude Dablon, who was a careful observer of Nature, states, in his relation of 1671 , that the region about Lake Huron was the most noted for its abundance of fish, since, as he says in savage parlance, this is its native country. (C'est la ou est son pays.)

It is to be supposed that he includes, in this statement, the achigan, with which he was perfectly familiar.

In addition to the foregoing facts, exact scientific investigation shows that the small-mouthed bass, unlike its relative, the large-mouthed bass, flourishes only in clean water of a temperature varying from $50^{\circ} \mathrm{F}$. to $60^{\circ} \mathrm{F}$.

If the temperature changes, even a few degrees, outside of these limits, the fish rapidly disappear.

It is for this reason that its habitat is bounded by welldefined isothermal lines, and that it seldom occurs in the cold waters of Lake Superior or of the northern portion of Lake 
Huron, or in some parts of Lake Michigan and Lake Ontario, whereas in the shallower waters of Lake Erie, and especially of Georgian Bay, it is found in great abundance.

It is for this reason, also, that it quickly disappears from artificial porids and inclosed lakes where the temperature conditions cannot be satisfied.

Jordan and Evermann, in their work on North American fishes, seem to have been the first to recognize this fact, as they state that the southern limit of this fish is bounded by cool waters.

We shall not be far astray, therefore, if we locate the birth-place of the small-mouthed bass somewhere in the waters of Georgian Bay, which, on account of its peculiar formation and great extent, and in spite of the ravages of fishermen and anglers, may still be regarded as its home.

At the present day, it is to be found in abundance in some portions of the Great Lakes, and particularly in Georgian Bay.

In Canada, it is found chiefly in the province of Ontario, south of the height of land which separates the waters flowing into the river Ottawa from those which flow into Lake Huron.

It is rarely found in Quebec north of the Saint Lawrence, but occurs in Lake Champlain.

It is not a native of the eastern provinces, but has been artificially propagated in New Brunswick. In the west it has been found in the Rainy River district, but not in Manitoba, nor in any of the waters draining into Hudson Bay. According to Evermann it is found in the following states of the Union, where in many cases it has been introduced artificially:

Maine, New Hampshire, Vermont, Massachusetts, Rhode Island, Connecticut, New York, New Jersey, Pennsylvania, Maryland, Virginia, West Virginia, Ohio, Kentucky, Tennessee, Indiana, Illinois, Michigan, Wisconsin, Minnesota, 
Iowa, Missouri, Arkansas, Indian Territory, Oklahoma, Kansas, Nebraska, North Dakota, and South Dakota.

It is possible that it may occur in certain places in Mississippi, Alabama, Georgia, South Carolina, and North Carolina. It has been introduced also into California, Oregon and Washington.

The comparatively small area, bounded by the parallels of latitude 40,50 , and by the lines of longitude 70, 95, may be considered as the region where it is living under proper conditions.

Outside of this area it may be propagated, but in all probability not with continued success.

NoTE. [It has been transplanted in England and Germany, small fry three inches in length having been carried across the ocean in tanks specially prepared for the purpose; but many died on the way owing to the difficulty of keeping the water, during the long journey, aërated and cool. The fish seem to have thriven well for some time but finally died out, probably owing to improper food and lack of attention. In a letter received from the present Marquis of Exeter in August, 1906, he says that some large and small-mouthed bass were imported by his grandfather in 1879 and were placed in a small lake on his estate near Stamford. They grew rapidly, some reaching, in a few years, a weight of four or five pounds; but they gradually disappeared, and the last one was seen in 1898 or 1899 .]

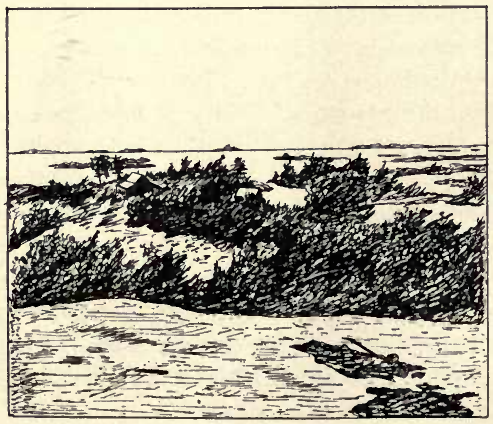




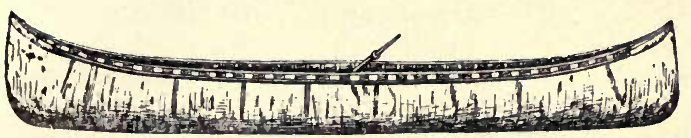

CHAPTER II.

HABITS.

W

ITH the exception of the speckled trout, no fish are so fond of clean, cool water as the small-mouthed bass. Unlike their brethren of the large-mouthed species, they delight in water flowing over clean sand and rock; and it is only when hard pressed for food or frightened by storms that they resort to weed-beds and muddy pools. In small inland lakes they may always be found wherever there is the least sign of a current, or where eddies form in narrow channels between islands, and around broken rock, where, owing to the conformation of the surrounding land, the water is more or less agitated. At the entrance of creeks or of small streams, especially if the water be pure and limpid, they may generally be found for days together.

In running streams they may be seen on bright days, their heads directed towards the current, their golden fins wavering ever to and fro, their mouths half-open, and their crimson gills moving gently in and out, revelling in the clean water and liquid motion; and they will keep themselves suspended in mid-stream apparently for the mere pleasure of living in aërated water.

In the heat of a summer's day they generally resort to sheltered spots, where they hide until the sinking sun, with its long shadows, enables them to emerge from their hidingplaces and obtain food. As a rule, they feed from two hours before until an hour after sundown, probably as long as they can see their prey. Just about dark, when their only chance of obtaining food is by watching the top of the water 
against the comparatively bright background of the sky above, they may be seen taking flies from the surface of still water. Their presence may be recognized by the characteristic swirl which is always seen when they are feeding in this way; they do not jump, like other fish, but move in a semi-circle and seize the fly or insect without emerging from the water.

In very rough weather or during a violent storm, they appear to become frightened, and seek deep water or hide themselves in a muddy place, which they may not abandon for two or three days; when they emerge from their hidingplaces they are ravenously hungry and bite freely, but do not put up a great fight.

And it may be said here that the fighting qualities of bass depend largely on their environment. Those which live in dead water, and have no access to running streams, naturally will not have the necessary exercise to make them active. No doubt, under such conditions, where food is plentiful and exercise rare, bass grow very large; but their flesh is not as delicate and they certainly do not fight as gamely as those of other localities which spend the greater portion of their time in water which is in constant motion. In inclosed lakes, without large inlets or outlets, the skin of the bass is jet-black, and its flesh under the back fin often filled with worms. On the contrary, those which live in rivers, streams, and large lakes, supplied continually with clean water, do not grow to such a size as in smaller confined lakes, on account of the distance they travel in search of food and the difficulty of obtaining it in rough weather; but they are much more active, their skin brighter, and their flesh infinitely more fit for use than in the case of those living in dead water. Judging from my own experience of more than twenty-five years, I may safely say, without the least trace of exaggeration, that there are no black bass any- 


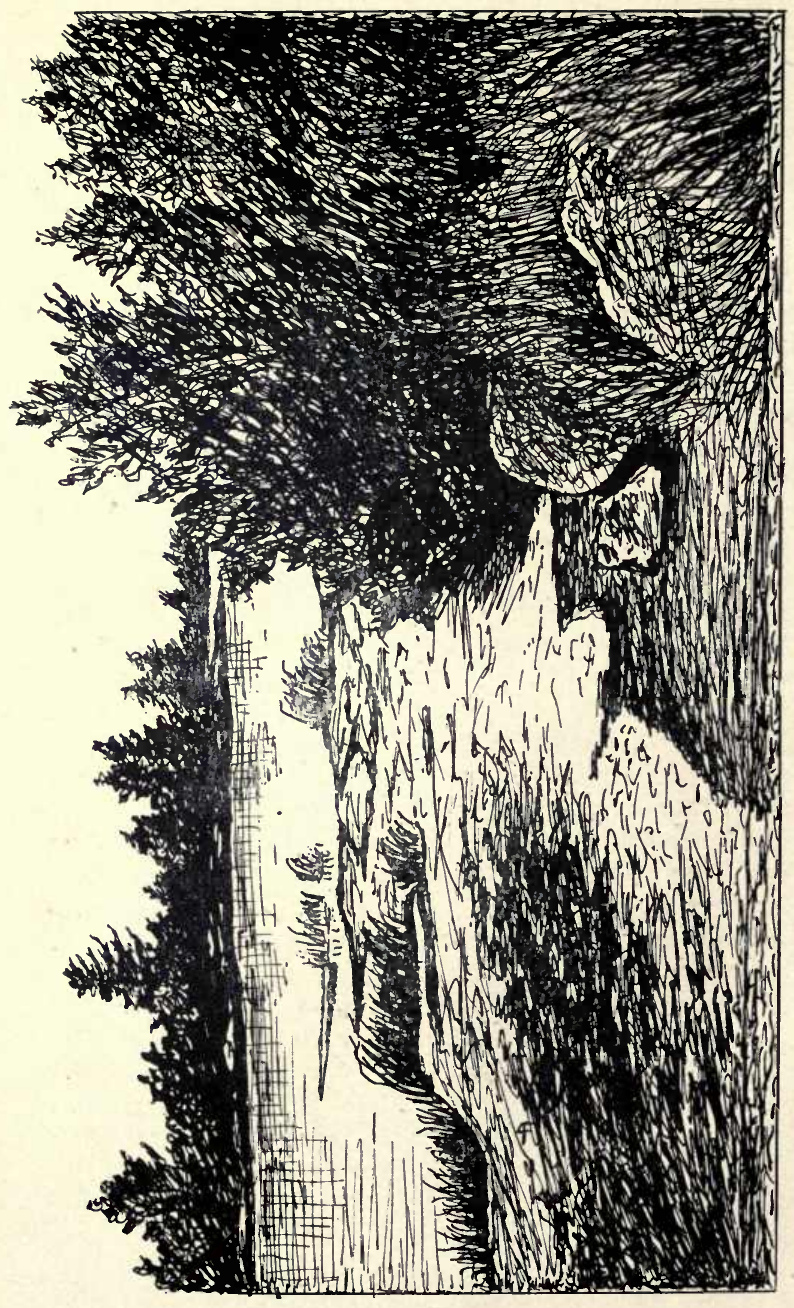


where to be compared, from an angler's point of view, with those which haunt the rocks and shoals of the eastern shore of Georgian Bay. Owing to the numerous islands and reefs lying along this shore, together with prevailing westerly winds, which keep the water always in motion, strong currents run in all directions, the result being that the bass there differ entirely from those which live in comparatively still water, their skin being a bright olive green, clean and shining, the belly pure white, and the eyes crimson; living in water which is in continual motion, they become exceedingly strong and active, and, as an article of food, they are unsurpassed even by the speckled trout.

In large expanses of water like the Great Lakes bass are gregarious and migratory. This is true to some extent even in smaller lakes. After the spawning season is over, in the spring, they collect in shoals, usually from ten to twenty, but occasionally containing as many as fifty fish, and swim about from place to place in search of food.

The composition of these shoals varies considerably: they may consist of a leader, either male or female, generally a large fish of two or three pounds in weight, and a number of smaller fry varying from a pound downwards to seven ounces; or, they may be all of a uniform size.

Very large fish are seldom found with these shoals; and what impresses one most, in these migrations, is the fact that the females predominate. The angler who takes a shoal of bass from a single hole will find, if he cares to make the necessary observations, that seventy-five per cent. of such a shoal will be females. Whether this is on account of their being more numerous than the males, or for some other reason, it is impossible to determine with any degree of accuracy.

Sometimes stragglers or solitary bass remain in one spot for a length of time; these are large fish of over three pounds in weight, and more frequently male than female. They seem to prefer solitude and rely on their own exertions. 
They are very wary, and usually choose some spot well sheltered from wind, near a point of land or high rock, in deep water, where there is a hiding-place in which they may lie in wait for food.

They are invariably jet-black, as one would naturally expect, owing to their remaining in deep water and shadow: and are often wormy.

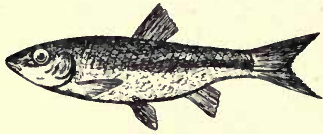

Red-nosed Minnow

A probable explanation of the preponderance of large female bass in shoals, as well as of the fact that the stragglers or solitary fish are nearly always of the male sex, may be, that, after the spawning period is over, the male fish guard the nests for some weeks, while the females roam from place to place and gradually collect together the smaller fry which are not old enough to spawn; the shoal thus formed, in all probability, remaining intact until the first appearance of cold weather; while, on the other hand, the male fish, after the guarding process is finished, distribute themselves according to their fancy and wander about alone.

Regarding the movements of bass when autumn approaches and the temperature of the water falls suddenly two or three degrees, not much is to be said, except that they form into very large shoals of several hundreds, irrespective of size or sex, and hibernate during the period of extreme cold, imbedded in mud, or under sunken logs, or in deep water amongst close-growing weeds.

They are never taken in the depth of winter. I have made extensive inquiries on this point, and all the anglers and fishermen, from whom I have sought information, have told me that they have never seen a bass taken by net or otherwise during the extreme cold of the winter months. That they hibernate seems to be proved by the fact that 
when they reach their spawning beds in the early spring they are covered with snail-shells, leeches, slime and mud.

Whether or not they return to the same spawning beds every spring is not known; but, judging from the fact that during their summer migrations they seek periodically wellknown feeding grounds, it is probable that, after the manner of birds, they frequent from year to year the spawning grounds with which they have become familiar.

When hooked, they always rush to the top of the water and jump to relieve themselves of the hook, except when they gorge the bait: in this case they "bore" down deep,

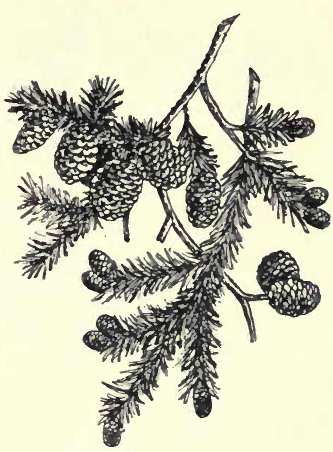

Black Spruce like the salmon trout, seldom approaching the surface. Statements have been made about the great height to which a bass will jump; but from many trials I have made with them, running on a slack line, I think one foot and a half is an outside limit. The fish usually leaves the water at an angle less than forty-five degrees, and, granting that its velocity is ten feet a second, it would be a physical impossibility for it to jump much more than one foot in height.

If, however, the angler is desirous of making it jump higher, he should keep a tight line and use a long stiff rod; he may then have the pleasure of seeing his fish rise as high as four or five feet; but in this case, it is the angler, and not the fish, that does the work.

The bass does not nibble at a bait, but first approaches and inspects it, then retreats, and suddenly dashes at it from a distance, seizes it at one gulp, and swims steadily 
away. The experienced angler has no difficulty in recognizing the characteristic strike thus produced.

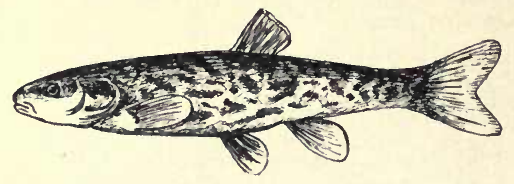

Black-nosed Dace

Frequently, when one of a large shoa 1 is hooked and is being played by the angler, who directs its motion to and fro, it will be followed in its rushes by two or three others, sometimes by the entire shoal. Careful observation shews that they do this with no intention or hope of securing the bait, which is usually thrown off the hook if it be a minnow or frog, or else is concealed from view in the mouth of their unfortunate companion; apparently their performance arises merely from a spirit of imitation.

It seems clear, however, from this strange procedure that the bass when hooked either has no sensation of pain or else is incapable of communicating with his mates; and also, that the latter have no means of realizing that their companion is in distress, a fact which seems contrary to all the laws of self-preservation and instinct.

The only analogous case, of which I am aware, and one which has always seemed to me inexplicable, is probably familiar to those who have tried to shoot the small fresh water tern, a bird that is extremely wary and rapid in its flight, living on small fish, which it catches along the shores of rocky lakes, hovering above shallow places until it sees a shoal of minnows, when it dives down from a great height, sometimes of forty or fifty feet, and secures its prey alive.

One would suppose that such a bird would be endowed with remarkable instinct, as it undoubtedly is under ordinary conditions; and yet, if one happens to fire into a flock of them and hits a single bird, its companions imme- 
diately hover above the dead or wounded bird, and fly about regardless of the approach of man or of any danger.

The whole flock may then be shot, one after another, with the same ease as if one were killing chickens in a hencoop.

The bass, like all other fish, is a voracious feeder, especially when small, and when not more than an inch or two in length begins to exhibit cannibalistic tendencies, devouring its weaker brethren with impunity.

The following experience, which is by no means uncommon, may serve to illustrate this fact :

On e afternoon I had been

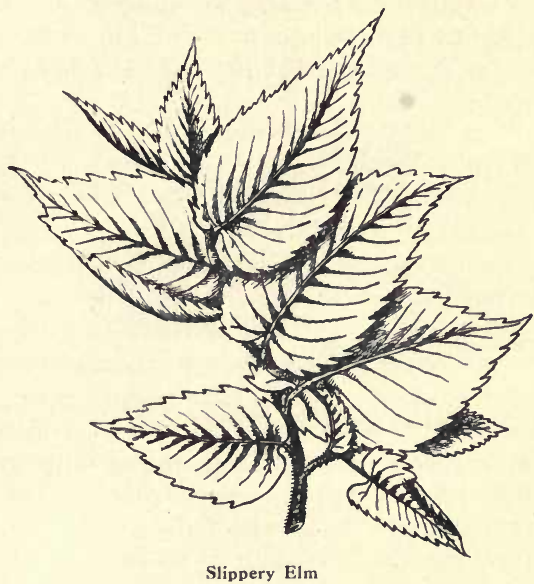

casting for bass with frogs near a sunken rock, when suddenly I felt a strike, and although I gave the fish ample time, he escaped, evidently having seized the frog from behind, contrary to their usual habit. A second frog disappeared in a similar way, and then a third. I suspected by this time that I was the victim of a solitary fish or straggler, who was evidently determined to obtain a full meal at my expense, so I lashed a fourth frog to the hook, with thread, in such a manner that the legs were free, but that it would be impossible for the fish to get the bait without being hooked. This frog had scarcely touched 
the water when it was seized, and eventually I landed my fish. One frog was still on the hook, but there was a second one in its mouth, a third well down its throat, and the fourth I found afterwards, on returning home, in its stomach. The combined weight of the four frogs, which it had attempted to swallow, was nearly six ounces, and the bass itself just weighed one pound.

Bass seem to experience little or no sensation when hooked, and

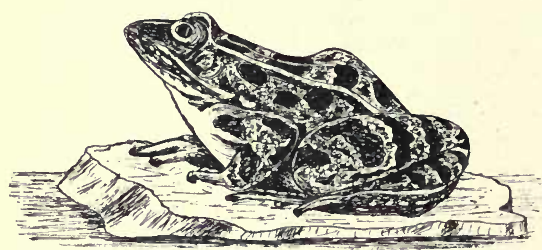

Leopard Frog struggle apparently, not from pain, but with the sole object of gaining freed o m. Anglers who have had much experience with this fish know that the same bass will return again and again to the bait after it has been hooked and has escaped; in fact, it is no uncommon thing to take bass with one or two hooks embedded in their mouths, the result of previous struggles.

7 Regarding this point, an incident which happened during the summer of 1906 is worthy of record, especially for the benefit of those who take serious objection to the cruelty of catching fish by means of a hook and prefer to take them in a net. Two friends of mine were fishing one afternoon in a small channel in Georgian Bay, between an island and the mainland, where a current ran with some velocity, necessitating the anchoring of their boat.

They were still-fishing with worms, one in the bow, the other in the stern, of the boat.

After catching several bass, they were sitting idly waiting for the fish to come in, when suddenly both felt a strike 
and both began to play their fish; and then, as usually happens, a large bass rushed to the surface of the water and jumped, shewing two lines attached to its mouth.

After a most exciting struggle, in which they seemed alternately to lose and regain their fish, they finally landed the bass in an inextricable tangle of gut, line and sinkers.

On inspection, they came to the conclusion that the bass had entered the channel seeking food; he had seen the first bait and had swallowed it, apparently with the greatest relish; then, swimming a little further, he had taken the other bait, the strong current preventing his action being felt until he began to swim away with the second bait.

The question then arose as to the ownership of the fish, which still remains undecided.

Judging from such experiences as the foregoing, one must come to the conclusion that bass are not, to say the least, seriously inconvenienced by being hooked in any part of the mouth or gullet; the only vital spot being the gills, which are so sensitive that, if touched with the point of the hook, they seem to lose some portion of their physiological utility, and the fish soon dies.

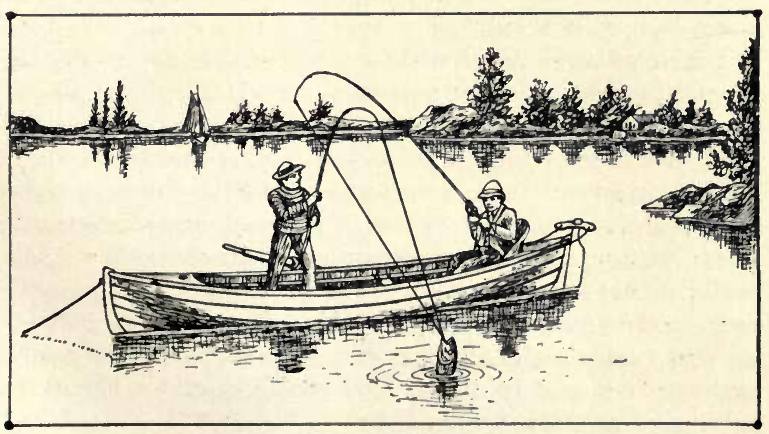

A Critical Moment 


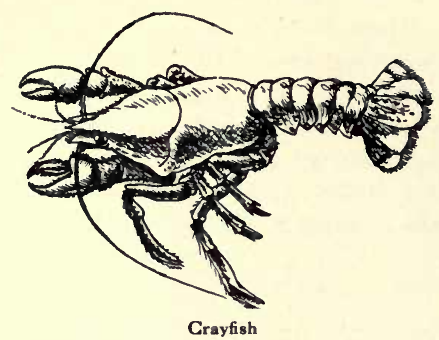

(From Photograph by B. A. Bensley)

\section{CHAPTER III.}

Food.

$\mathrm{T}$

$\mathrm{HE}$ food of the black bass, although dependent on locality, is limited in extent, and consists chiefly of live minnows and crayfish. An examination of its stomach, after capture, will show that, in the majority of cases, it has been subsisting on these two articles of diet, intermingled sometimes with several minute forms of life which apparently do not supply a very large proportion of its nourishment.

Although it prefers the young of the herring, small chub, shiners, or any of those minnows which have comparatively small scales and are therefore both palatable and soon assimilated; yet, occasionally one may find in its stomach a small perch, perhaps three or four inches in length. Owing, however, to the peculiar structure of this fish, with its large back fin and heavy scales, it does not seem to be either easily swallowed or quickly digested by the bass, and probably is only taken as a last resort. 
After a period of rough weather, during which the bass seeks deep water, its stomach usually is filled with organic matter, intermingled with mud. Whether this contains nourishment of any kind, or is taken merely in a medicinal way (just as some animals eat grass and earth when sick) is a question which can be decided only by expert biologists with the aid of the microscope.

Doubtless, when very hungry, it will, like other fish, eat anything which comes in its way; and so one finds, though rarely, that it has been living on crickets, moths, grasshoppers or other insects; if pressed hard, it may even

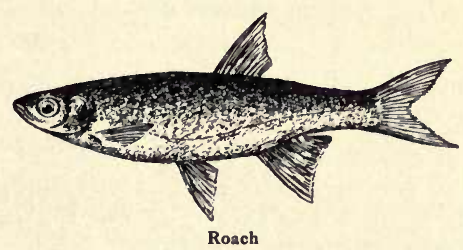

eat dead minnows or any kind of refuse; but, ordinarily, it is very fastidious and prefers to chase live minnows and crayfish and capture them alive. It is probably for this reason that still-fishing for bass is not usually very successful unless the bait shows signs of life; and although one may take them with dead minnows, pieces of clam, and even with dead worms, when they are exceptionally hungry, yet, as a rule, the bait must be not only alive, but arranged in the most tempting manner, in order to insure their capture.

This is particularly true on a bright day, in clear water, when, if a dead minnow be dropped amongst a shoal of bass, they may be seen approaching the bait, one after another, so closely as to give one the impression that they are 
smelling it, sometimes actually sucking it into their mouths and ejecting it with evident disgust; and then, suddenly, like a flash, they will all disappear.

Doubtless for this reason also it is difficult, though not impossible, to take bass with a trolling spoon. If one moves

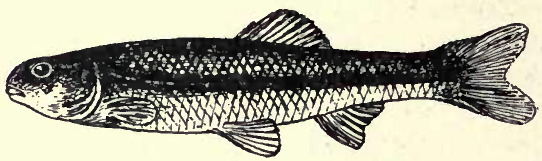

Fat-head Minnow

(From Photograph by B. A. Bensley)

slowly, the fish has ample opportunity to inspect the bait; if rapidly, so as to confuse its judgment, the chances are that it will, in striking, miss the hooks; so that, if one must get his fish by the barbarous method of trolling, he should be careful to regulate his pace, and use the very smallest of spoons.

As to the statement which has frequently been made, that frogs form a large portion of the diet of bass, especially in inclosed lakes, it is doubtful if such be the case.

Frogs live in marshy spots or near weed-beds where there is little or no current and the bottom is covered with several inches of slime and mud, and is strewn with dead branches

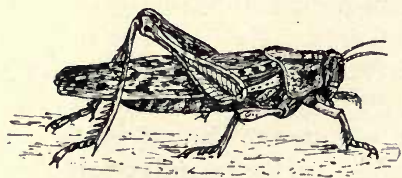
of trees and sunken logs;

in such places the water is stagnant, dirty, and warm, and is never frequented by the small-mouthed bass; although his near relation, the large-mouthed bass, haunts such 
localities, and, lying in the mud, close to shore, in three or four inches of water, lives almost entirely on the frogs which sport along the water's edge. When in the water the two varieties of bass are not easily distinguished from one another, even by experts; and it is on this account, no doubt, that reliable persons have frequently stated that

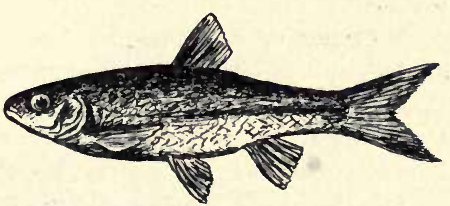

Silverside (Female)

Reduced to One-half Actual Size they had actually seen the small-mouthed bass catching frogs, mistaking it for the other species.

As evidence that frogs do not constitute an article of diet for this fish, I place on record here my own experience, which has extended over forty years, and has been varied enough to entitle it to consideration.

During this period it has been my privilege and pleasure to angle for bass in a great many lakes and streams throughout Canada; rarely a year has passed that I have not taken from one hundred to five hundred bass, in a legitimate manner, with rod and line; during the years 1870-1890, when there was no limit to the catch of an angler, and bass were very plentiful, I have taken as many

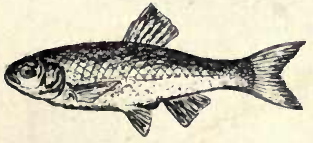

Silverside (Male)

Reduced to One-third Actual Size as one hundred in a single afternoon.

One summer, not long ago, I kept an approximate list of the fish I captured, and it totalled in the neighbourhood of one thousand.

I think I am safe in saying that during my life I have taken from five to ten thousand bass; and, as I have always examined the stomachs of my fish, I am able to state defi- 
nitely that $I$ have never found frogs therein, except in one or two cases where they had been stripped from my own hook by bass which I afterwards succeeded in capturing.

Whether or not this has been the experience of other anglers and fishermen, I am unable to say.

That bass will take a live frog as bait does not prove that it is accustomed to it as an article of diet; the reverse is indeed true, as is the case with animals.

On the other hand, crayfish, which enter largely into the regular diet of this fish, are not usually very effective as bait; in Lake Ontario, Erie, and Georgian Bay, where this is true perhaps to a greater extent than in any other locality, it is almost impossible to catch bass with the ordinary crayfish, however carefully one may arrange the bait; and yet, nine times out of ten, on examining the stomach of a bass, after capture, it will be found filled with these amphibious creatures in all stages of development.

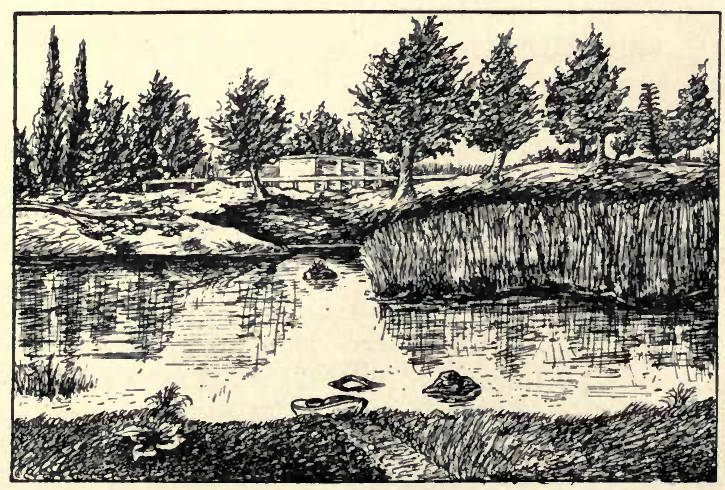

Frog Poud 


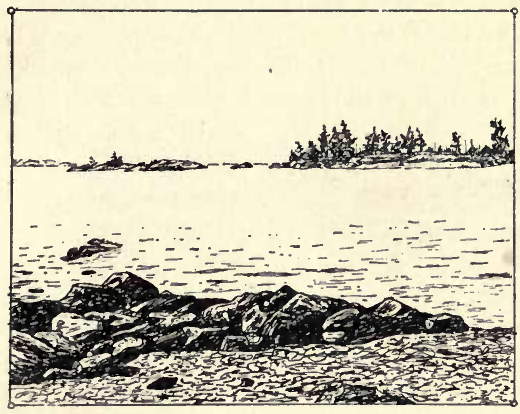

CHAPTER IV.

Where tO CATCh THE Black Bass.

I endeavouring to determine the most suitable. place for catching bass, one naturally should consider two questions: Where do the fish feed? To what spots, from habit, do they usually resort?

If their haunts are once discovered, the rest of the problem is easy of solution.

When an angler, therefore, finds himself on a small inclosed lake or alongside the banks of a running stream, or in the more difficult situation of being compelled to fish in a large body of open water, his first duty is to inspect carefully the surroundings in a boat, unless he is fortunate (or unfortunate) enough to sectre the services of a competent guide, who is perfectly familiar with the locality.

The expert angler seldom desires such aid, because, in the philosophical pursuit of the finny tribe, half the pleasure 
at least consists in discovering, without assistance, the favourite haunts of the fish.

In a running stream, whether large or small, the most favourable spots are likely to be those which contain quiet pools with eddies, in the

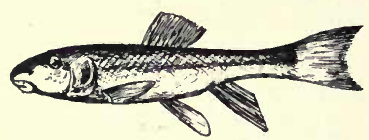

Young Sucker vicinity of sunken logs, or in the neighbourhood of projecting rocks, or where the stream narrows up suddenly and its bottom is strewn with boulders and broken stone.

At the foot of a chute, between the current and the return eddy, or in the eddy itself, one seldom fails to get a strike, even in unfavourable weather, although one is in danger of losing his line or having his rod broken by the voracious pike, which are in the habit of frequenting such places, where food is always abundant.

But the best place of all is where the stream makes its exit into a lake or large bay, especially if the current be not too strong. If one anchors in such a position, no long time will elapse before the fish are attracted by the bait.

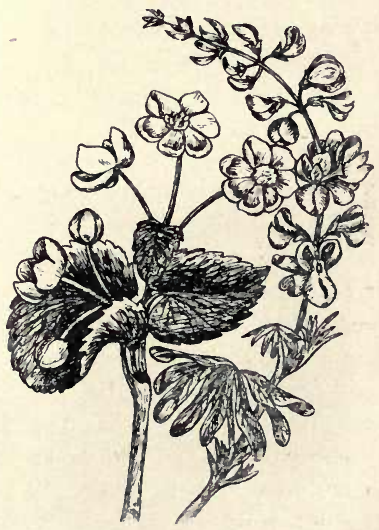

Marsh Marigold and Lupine

In a small inclosed lake, there is not much difficulty in catching bass, as the entire lake may be inspected in a few hours, and suitable 
spots chosen; the best being those in the vicinity of rocks or small islets, and at the inlet or outlet of the lake.

Occasionally one may take bass in hot weather in the deepest holes of a lake.

In a large expanse of water, however, the skill

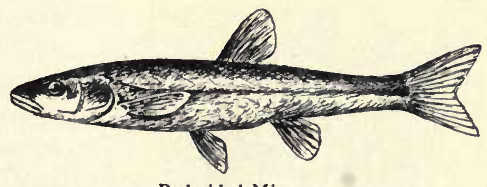

Red-sided Minnow of the angler, his patience, and powers of endurance are of much more moment.

Here the circumstances are quite different, as the fish travel long distances; and, although one may, by accident, have good fishing at a certain place on a particular day, yet one may return again and again to the same locality and never get a nibble.

It requires all the judgment the angler can summon to

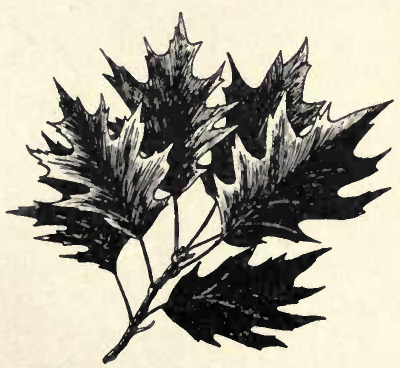

Red Oak his aid to fish in a large body of open water with continued success.

The a mateur who knows nothing about such fishing might go out day after day for a week and be quite sure, in his own estimation, that the fish had disappeared; and, yet, if he possess the necessary knowledge, he may go out at any hour of the day and be certain of enough bass to supply himself at least with an evening meal. In Canada, on the Great Lakes, this state of affairs exists to a remarkable degree; there, one must have the necessary time at his disposal, be 
fond of hard work, and have infinite patience, if he ever hopes to qualify for the honourable title. of expert angler.

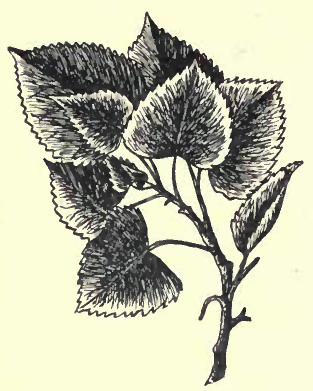

Neck-lace Poplar

In a large body of water the places which will be found most favourable for the taking of bass are at the entrances of bays, near the mouth of a stream, and in the neighbourhood of sunken reefs, which form with each other inclosed pockets with a bottom of mud and weeds.

Where there is an abundance of rough broken stone one is always sure of taking bass, especially in the afternoon or evening, just before sundown.

For the expert angler, who has served an apprenticeship of ten or twenty years in acquiring the necessary rudiments of an education which springs only from long contact with Nature, there is no place which compares, at least in variety of bass fishing, with the eastern shore of Georgian Bay.

From an inspection of the map of Lake Huron one can see that such a region is peculiarly adapted to be the home of the smallmouthed bass.

The shore extends for a distance of one hundred and twenty miles north and south; deep bays penetrate the land at intervals,

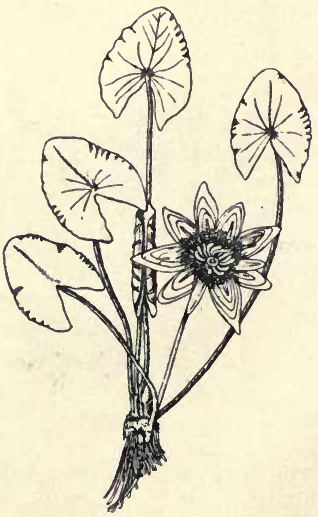
whilst numerous large and small streams flow into it, carrying down in their waters a supply of minute animals and 
organic matter sufficient to maintain in luxury an immense number of fish.

Georgian Bay itself is deep in the centre, with a bottom of mud and weeds, sloping gradually upon all sides towards the shore, and forming extensive sandbars, which are interspersed with countless reefs and islands, some large, others so small as barely to provide a resting-place for gulls, while
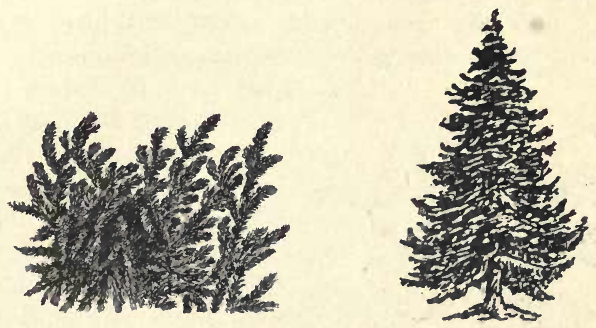

Canada Balsam

others again lie just beneath the surface of the water, a menace to navigation.

The bays abound in sand beaches, to which the fish go in the spring for the purpose of spawning, and what other countries are attempting to build up artificially on a small scale, with a large expenditure of time and money, is provided free for the province of Ontario by the hand of Nature.

Minnows in the shallow bays and ponds, and crayfish amongst the broken rock and stone, exist in millions.

As the prevailing winds are westerly, the water of Georgian Bay is being continually driven up against the eastern shore, and oscillations of the lake set in, producing currents which run, sometimes off shore, sometimes on shore, or even in opposition to the wind, causing the waters of the narrow channels between the islands to ebb and flow continuously, 
and thus not only distributing food for fish of all kinds, but also keeping the water clean.

In consequence of this the angler will always find the best fishing in these narrow channels, where, if he makes careful observation, he will notice a current running first one way and then the opposite.

The bass frequent these spots, generally in shoals of five to ten, lying in wait under some shelving rock for minnows playing near the water's edge or silver shiners swimming swiftly by, or for unsispecting crayfish as they creep, with out-

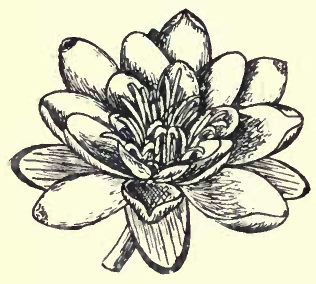
stretched arms, from stone to stone.

Shoal fishing for bass in Georgian Bay is perhaps the most difficult of all forms of fresh water angling. When a steady wind from any westerly direction is blowing, the bass, during the day, especially in bright sunshine, frequent what are termed by the fishermen "shoals," situated a mile or so from shore. These are shallow places, varying in area from ten to one hundred acres, and in depth from two to ten feet, protected by outlying reefs or small islands sufficiently to prevent the heavy swells outside from breaking in, but in such a way as to produce eddies and currents which keep the water in a continual state of agitation. Probably the fish frequent these shoals to secure the crayfish which are driven from the crevices of the rocks and are easily captured in rough water.

The sport here is always good, but exciting and sometimes dangerous; for it is impossible to anchor, and one must keep continually on the alert for fear of striking the bottom, which is strewn with jagged rocks of all sizes and shapes. In addition, the angler must be able to handle his boat alone, because, with an assistant rowing, he can never be sure of 
his cast landing in the right position; and so he must be an expert with the oar as well as with the rod.

And when a large bass is hooked he must be ready for any emergency, such as the line catching on the bottom, or the sudden appearance of a large rock lying with its pointed head just submerged, or of an unusually large wave which may break over his boat and fill it with water. The angler who is able to land his fish in such a troubled spot is entitled to call himself an expert.

In connection with bass fishing the most important fact

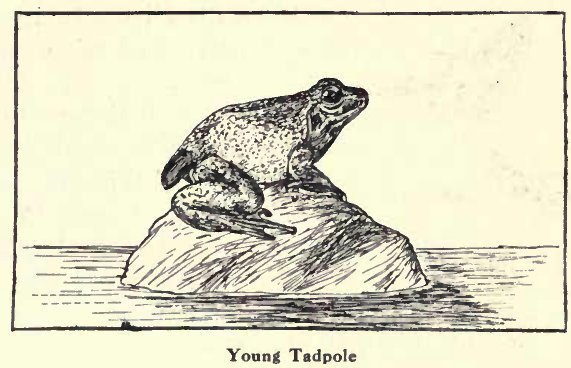

to remember is that, when feeding, the fish seek some favourite position, usually a hole or crevice, from which they may observe the surrounding water but are at the same time themselves concealed from view. They will lie in such a place for an hour or two, and then suddenly emerge and swim off rapidly to some other similar place.

They do not move about continuously while feeding, and for this reason one might fish for days together and, unless he happened to strike the very spot where bass are, he might never get a nibble.

Sometimes a dozen of them will lie, under a protecting shelf of rock, in shadow, for hours, darting out occasionally 
to seize a minnow or crayfish, but returning immediately to their hiding-place.

Nine times out of ten, when in common parlance the fish "begin to bite," it is simply because some slight change of position has exposed the bait to their view.

As an illustration of this I recall to mind a spot where I have been in the habit of fishing for bass during the past ten years. It is near a point of land, in shallow water, where a current runs, and where there is a sudden deepening of the water to about eight feet, so that a small hole is formed, in area about two feet by five, at the bottom of which lies a

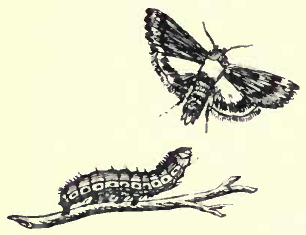

Tomato Grub and Moth boulder with a little crevice, which is perhaps a foot wide and two feet in length.

To the inexperienced eye it is the most unlikely spot in the world for bass. Passing it, one would see shallow water, a smooth, rocky bottom, no weeds, mud or any indication of fish; and yet I have taken so many bass from that small area of ten square feet that I hesitate to mention the probable number.

I found it useless to fish anywhere else in the vicinity. I have tried for hours, and even for days, but without success.

The hiding-place in which the bass lay was so confined, and the fish remained so still, sometimes for hours at a time, that, unless bait was dropped right under their nose, they failed to see it; a distance of a few inches one way or the other was sufficient to prevent it being visible to them. All of which goes to prove the value of exact location.

This habit of hiding is not confined to the small-nouthed bass, being common to all predatory fish, such as the pike, maskinonge, rock bass, etc., which prefer live bait; but it is more marked in the case of the bass, because this fish, unless very hard pressed by hunger, will refuse dead bait of any 



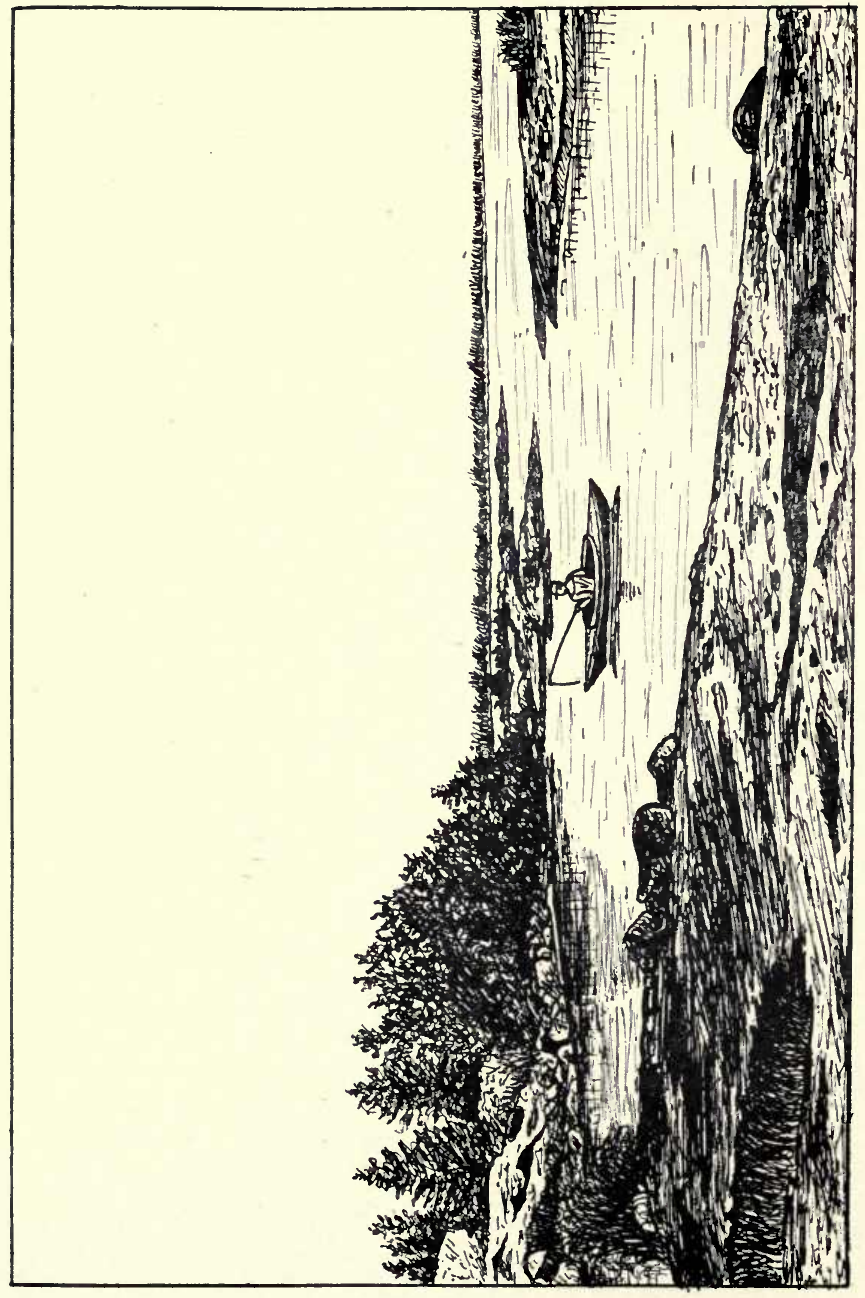


kind, whereas the other species do not hesitate to eat anything which appeals to them in the form of food.

Even in the case of other fish which are non-predatory, the hiding instinct is highly developed and forms probably the chief feature in their every-day existence.

In connection with his statement I relate here the following experience:

I was sitting, one summer evening, near the edge of a small pond, cleaning some black bass; and, when I had finished the operation, I proceeded to cut them up into suitable pieces and wash them in a small hole, where the water was about a foot in depth.

Here I noticed a commotion at the bottom, which was nuddy and covered with green weeds; and occasionally I saw small minnows darting to and fro amongst the broken stone which lay in the vicinity.

Sitting down quietly close by, I waited patiently for some time, and soon, as the water became clear, I observed a number of small fish,

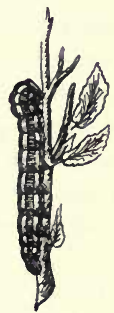
about an inch long, feeding on the ninute particles of gelatinous matter which had been detached from the pieces of bass by the process of cleaning and hung suspended in the water.

Presently a few larger minnows appeared, and then one or two small perch; but the least movement on my part caused them all to vanish.

I then placed some larger pieces of skin and flesh just at the edge of the water and sat down again. Soon the minnows re-appeared, and then a few perch, of larger size than formerly, all busily engaged in eating the refuse; but sometimes a perch would vary the performance slightly by gobbling down an unfortunate minnow. Suddenly, from under a large stone, a gigantic crayfish, about nine inches 
in length, emerged, and, crawling slowly to the shore, seized a large piece of skin and began to drag it back to his hole; with his slimy green shell, his long snaky-looking feelers and claws, and his bright protruding eyes, he was a most diabolical object, and produced in me a mixed feeling of fascination and disgust. A slight motion of my hand above the water, and immediately, like a flash, all were gone, each to its hiding-place, from which, no doubt, observations were taken until they were confident that no danger existed.

A few minutes of quietness, and then the same performance was repeated; but, this time, another crayfish of smaller dimensions appeared on the scene, and a struggle began between the two amphibians for a large piece of skin. They finally became bolder, and, reaching dry land, fought for the food like two dogs, until the smaller crayfish became tired and scrambled off in search of other pieces which were being appropriated by the larger perch.

In a short time, probably not more than ten minutes, the space about me was literally alive with all kinds of life, minnows, perch, garpike, small catfish, crayfish, sunfish, rock bass, all engaged in eating or fighting; and where formerly everything was as still as death, and where a casual observer would have said that no life existed, a veritable menagerie was present, all intent in the struggle for existence.

The climax was reached when a large pike, which I had not observed, but which must evidently have been hiding under some lily pads a few feet away, rushed into the group of combatants, and seizing one of the largest perch, swam away.

The disturbance created by this voracious monster evidently frightened the community thoroughly, for, although I waited some time for a renewal of these interesting scenes, not a single creature re-appeared. 



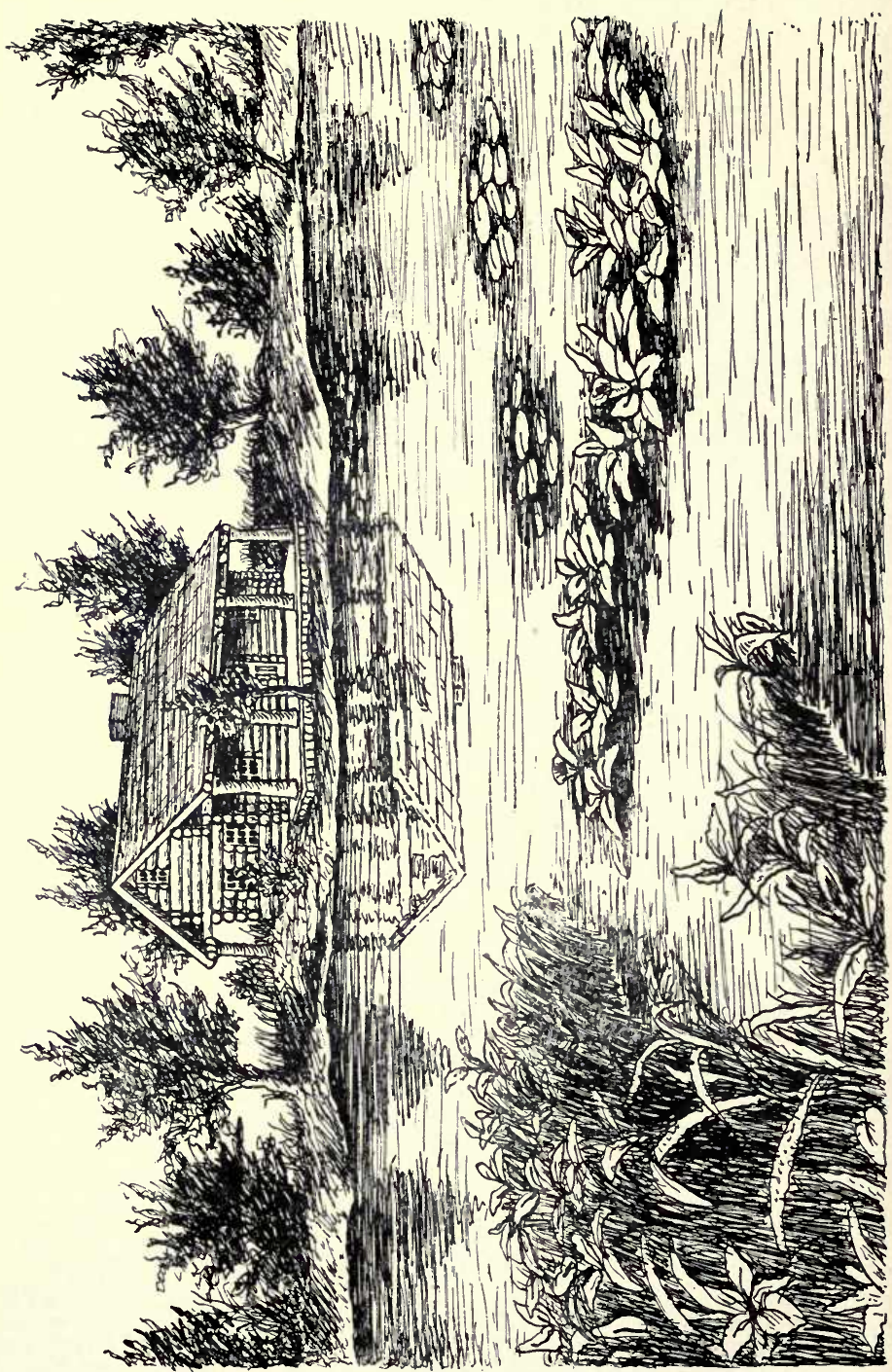




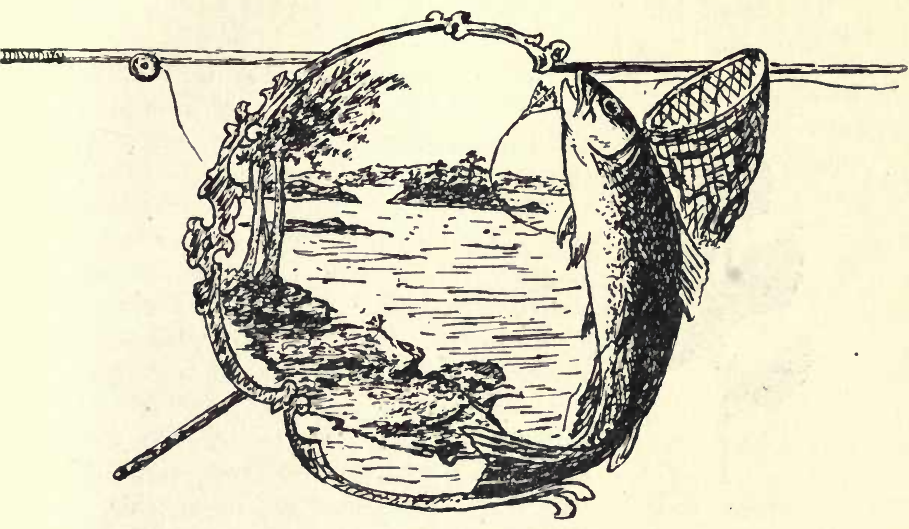

CHAPTER V.

How to Catch the Bass.

D EGARDING methods of' taking bass and the best kinds of tackle and bait, each angler is a law unto himself; and, on the supposition that one knows where bass are to be found, an outfit is of secondary importance; as far as getting fish goes, the boy with a cedar pole, some twine, a limerick hook and a worm, can, under such conditions, compete successfully with the expert angler.

There are so many different kinds of rods, running all the way from bamboo to steel, that it is difficult to recommend, particularly to those who profess to know something of angling, any special brand.

For general use, the ordinary unsplit bamboo, about seven feet long, is probably the most serviceable. If one 
is accustomed to fish alone, the rod should not be more than this length, as there will be difficulty in capturing the fish with a landing-net; because, one has to play the

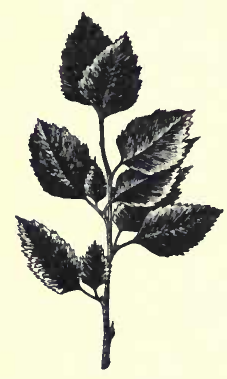

Water Birch bass with one hand while using the landingnet in the other; and with too long a rod this cannot be safely accomplished.

Many experiments have convinced me that a rod from six feet to seven feet in length, varying with the reach of the angler, is the best. To get the exact length of rod suitable for one's particular reach, sit in a chair, and with a landing-net in one hand reach out as far as possible without straining the muscles; in the other hand hold the rod, and move the two hands about in a horizontal plane so that the rod and one arm form, with the landing-net and the other arm, the sides of a triangle. Then the tip of the rod should be exactly at the centre of the landing-net.

Even when the landing of the fish is made by an assistant a short rod is more convenient.

I advise all anglers, however, who wish to become experts, to fish alone.

Apart altogether from the pleasure of discovering, alone, the favourite haunts of the bass, nothing is so demoralizing to the whole art of angling as conversation, especially in the form of the interrogative mood; so that, if one must have a guide, let the latter be one not given to expressing his

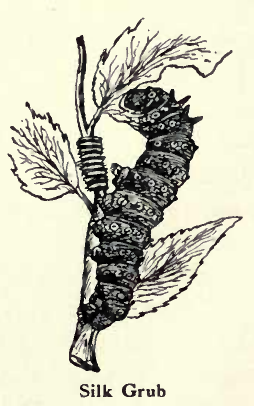
thoughts in language, and therefore preferably one with Indian blood. 
The more people one has in a boat, the greater the chance of conversation, and therefore of argument. When a number fish together from a boat, one person always gets the best bait or the best fishing; the others become impatient; lines become entangled; fish escape, always the largest; and, unless a good supply of provender be taken along, there is great danger of a quarrel.

Therefore I advise all those who go fishing in a boat with a number of friends, and who wish to avoid trouble to take along plenty of meat and drink for the unemployed, the unsuccessful, and the incompetent.

I have made it a rule always to fish alone, but several times have been persuaded to take companions along with me; the last experience I had, however, convincing me that $I$ would

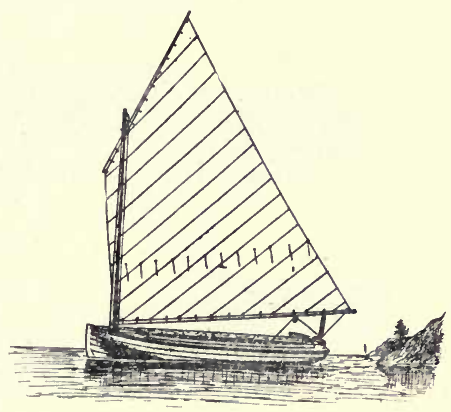
never attempt it again.

A very intimate friend proposed to me one day that we go fishing in Georgian Bay amongst a long fringe of rocks and sunken reefs which lie between the mainland and the Giant's Tomb. As the distances to be covered were great, he insisted that we should take a sailing dinghy, about fourteen feet in length. Fearing the consequences of fishing from such a craft, I tried to persuade him to change his mind.

But he was obstinate on the point, and I yielded, not without misgivings.

We started from shore about ten o'clock in the morning with a complete outfit: plenty of extra rope for anchoring, 
a pail of frogs, another of minnows, and a box of one hundred worms; also, extra hooks, lines, and a spare rod.

Fortunately, I did not overlook the provender: pork and beans, hard tack, as well as pipes, tobacco and matches.

The wind was south by west, the sky overcast, and the air warm and humid: an ideal day for fishing.

We sailed slowly out to a set of reefs known as the Three Sisters, and I advised anchoring in a certain spot; which was accomplished, not without some difficulty, on account of the strong currents running over the sunken reefs.
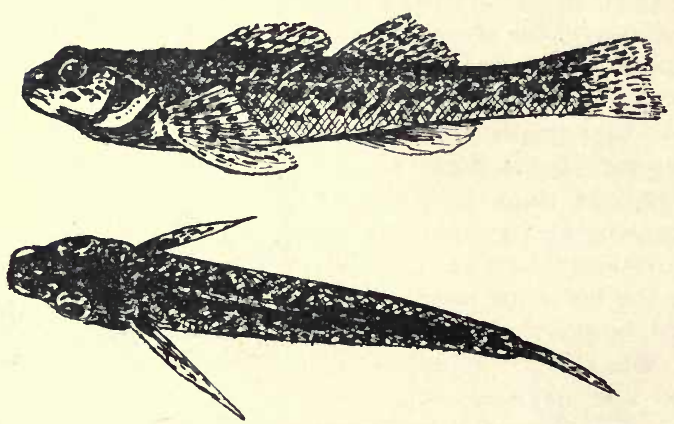

Spotted Darter

(From Photograph by B. A. Bensley)

While my companion was engaged in this work I got my rod and line ready, baited my hook with a frog, and landed a fish in less than a minute.

Knowing the nature of the spot, and that it was frequented only periodically by small shoals of bass, which never remained there for any length of time, I hurriedly baited my hook again and landed a second fish, and soon afterwards a third.

My companion, who was having some difficulty in fitting 
together an elaborate rod and reel, immediately objected that I was not giving him a fair opportunity; so I landed one more, making four, and helped him to arrange his rod and line, baited his hook, and agreed to land his fish.

He then wanted to exchange places with me in the dinghy, and in doing so the boom swung around, knocked the pail of minnows overboard, and we nearly capsized the boat.

Whether the shoal of bass were frightened by the noise, or had a free meal of minnows, sufficient to satisfy them, I do not know. We caught no more fish there.

Soon iny friend became impatient and insisted that we go further out.

I agreed to this, but the wind had now dropped and some rowing had to be done.

It had been previously arranged, owing to my objection to the dinghy, that in case there happened to be no wind my friend would do all the rowing; but somehow or other the lot now fell to me.

So I rowed about a mile further out, and we anchored again, in a shallow spot, where there was a heavy undertow and consequently a heavy strain on our anchor rope.

Here we fished ten or fifteen minutes without getting a nibble; and, as the wind began to blow fresh again and the dinghy was pounding up and down, we decided to sail to the nearest reef and have lunch.

Being in the bow of the boat, I was busily engaged in hauling up the sail, when suddenly the anchor rope parted and threw the boom up against the stern of the boat, knocked down the pail of frogs, which began scrambling all over the bottom boards; and we shipped about a barrel of water.

However, we gradually got under way, and I occupied the next ten minutes in bailing out water and trying to catch the frogs, most of which had secreted themselves in various crevices of the flooring, and defied capture.

Lunch, however, made things assume a different aspect, 
and after we had polished off everything in the form of "grub" and had a "smoke," we decided to try our luck again.

We sailed to a group of reefs, fairly well protected from the wind, and anchored in about eight feet of water.

I have but a faint

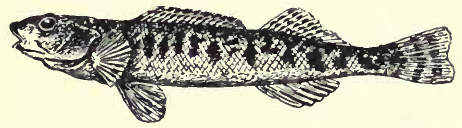

Striped Darter

(From Photograph by B. A. Bensley) recollection of all the accidents which happened at this place; but if my memory serves me right we lost all our ropes and anchors, hooks and lines, and the butt and reel of one rod, to the accompaniment of some very disagreeable conversation.

We got three bass, though more by good luck than by expert fishing. The final catastrophe came about three o'clock, when the pin holding the iron centreboard of the dinghy worked out and at the same time our last anchor rope parted, and as the dinghy drifted quickly amongst the shallow rocks the centreboard became wedged in a crevice between two boulders. This necessitated immediate action, so we both jumped into the water, and in a confusion of surf, wind and some profanity, finally succeeded in getting the dinghy free.

We then started for home, and during the voyage I dilated upon the advantages of fishing from a sailboat, much to the

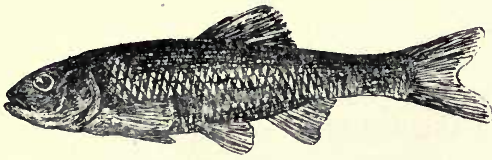

Silver Shiner

(From Photograph by B. A. Bensley) disgust of the other occupant of the boat.

We landed at five o'clock, having caught seven bass in seven hours.

Even when one does not fish from a boat, but walks 
along the bank of a stream, or wades in the water, a long rod is not very convenient. The only advantage jointed rods have is that they are portable; in other respects they are not as convenient and certainly not as serviceable as the unjointed rods.

Of the multitudes of reels which one finds in the stores, the simplest is the best.

An ordinary nultiplying reel with a friction brake is all that the expert angler really requires. Various forms of automatic reels are advantageous at times, especially in calnı water; but, in the long run, they are sure to get out of order just at the critical moment.

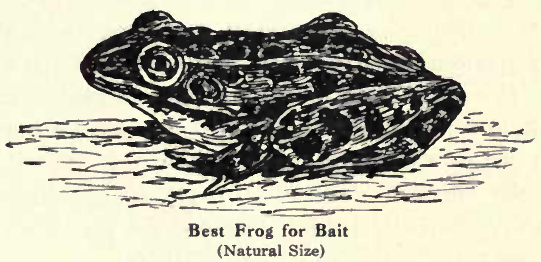

Elaborate and complicated reels and rods possess, however, the great advantage of giving much pleasure and occupation to the majority of fireside anglers and harbour sailors, who have formed, during the long winter evenings, the life-prolonging habit of building castles in the air.

Regarding lines, I have found that, for continuous fishing, the fine braided linen line is the best; and, although it is not as durable as the braided silk line, it is cheap and may therefore be easily renewed. Oiled lines of any material, unless they are very carefully made, and thoroughly examined and dried out each time they are used, soon rot and become unreliable.

Of the various kinds of bait, artificial and natural flies, and insects, and deadly-looking trolling-spoons, the best is 
the live minnow or the small green frog, the former of which constitutes, in the life of the bass, its true diet, the latter being properly a luxury or bait.

Either of these, used in conjunction with a small hook, an inch or an inch and a lialf in

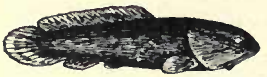

Young Dog-fish length, will generally be found effective.

Any of the more attractive minnows may be used, but the delicate silver shiner or the young of the herring are to be preferred.

The young of the dog-fish are excellent bait and possess the advantage of being tough and hardy. They will live for hours, even in comparatively warm water, and may be kept in an ordinary wooden pail for days, if the water be renewed occasionally; they are, however, difficult to procure, except in the early part of the summer, when they may be seen in shallow bays, with mud bottom, wandering about in shoals of two or three hundred.

The river chub or creek chub may be substituted for the shiner, being more durable, and not so much affected by hot weather.

At times, even a small pickerel or perch may be used to advantage; but they should not be more than two or three inches in length, the smaller the better.

In the fall of the year, when the water begins to get cool, and shiners and other delicate minnows are scarce, the small perch furnishes an excellent bait for bass, as it is very tenacious of life, and attractive in appearance, especi-

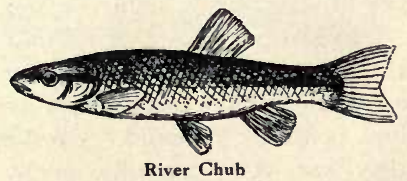
ally if taken from clean water. But there is one objection to using perch in the autumn, namely, the attraction which it offers to pike. 
There is no bait so deadly for pike as the live perch, probably because it contains more solid food than any minnow of equal size, and the pike is a fish wh i ch evidently believes in quantity and not quality.

The chances are, therefore, nine times out of ten,

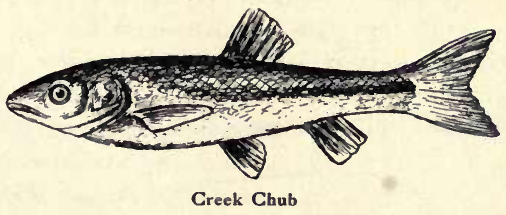
that, when angling for bass in the fall of the year with a dainty looking perch, one will find, on getting a strike, a huge pike at the end of the line, with perch, hook and several inches of gut down its throat; the task of removing such a monster from the line counterbalances any advantage that may be derived from angling with perch.

The minnow should be placed on the hook so that the barb passes first through the under part of the mouth and

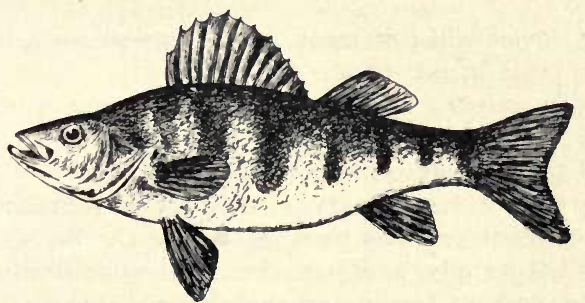

Yellow Perch

then through the upper part; this allows freedom of motion, and the minnow swims about naturally, with the point of the barb upwards.

The bass usually approaches a minnow from one side, and, swimming up to it, inspects it carefully; then, backing up a short distance, it rushes at the bait, swallowing it head 
first; so that, if the bait be properly arranged, the bass will invariably be hooked in the upper part of the mouth, and its chance of escape reduced to a minimum.

But the greatest care must be taken to allow sufficient time to elapse after the strike is felt, so that the bass may get the minnow well into its mouth; otherwise it is sure to escape, while the minnow will be set free.

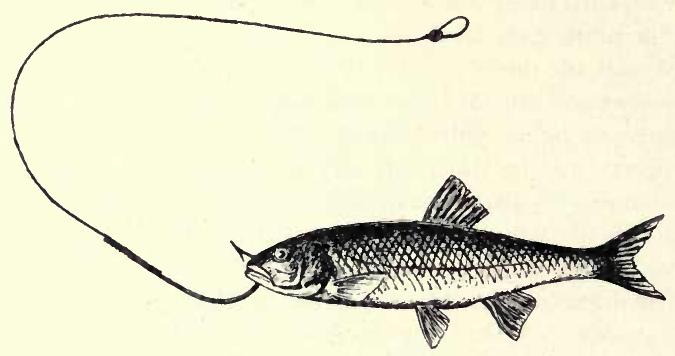

The novice will lose many a fish, as well as the bait itself, by being in too great a hurry.

I have watched the capture of minnows by bass so frequently, that, for the benefit of the amateur angler, it may be well to give here my experience.

The bass, if very hungry, often rushes at a minnow and seizes it before one has time to observe the details of the attack; but usually, as stated above, it swims slowly up on one side, perhaps backing up slightly, and then swims suddenly around to the other side, but always keeping its head directed at a right angle to the line of motion of the minnow, and finally approaches so that it is within an inch or two of the unfortunate bait; so close, in fact, sometimes, as to give one the impression that it possesses the sense of smell.

It will then suddenly open its mouth and seize the min- 
now crosswise, so that its jaws close over the gills, the hook being at the end of the minnow's snout, but not in the mouth of the bass.

It then begins to swim away; and it can be readily understood that this is the crucial moment; for, if the angler, when he feels the bait being seized and drawn away steadily, gives a sudden jerk, he simply draws the hook out of the tender mouth of the minnow, which the bass then carries away.

He should control himself and wait patiently for the next effort of the bass, which is to stop for an instant, give a sudden little gulp, when the bait and hook both disappear down his throat.

It is just at the instant when the sudden gulp is made that the angler should tighten his line; and nothing can teach him this but experience. The novice must practise some time before he can determine, by the sense of touch, what is happening at the other end of the line; a little patience, however, is all that is needed; and, with any kind of a light rod, he will soon be able to recognize

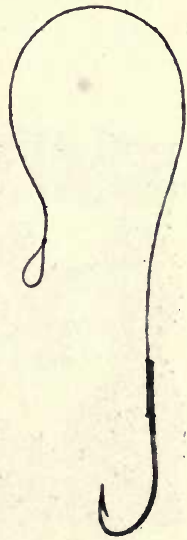

Basshook for Minnow or Fros (Slightly reduced) the proper instant at which to hook his fish. To give too much time is almost as bad as to be too hurried; delay is dangerous when carried beyond a certain point; because, if the point of the hook happens to touch a sensitive part of the gills of the bass, it will at once make a rush, casting the minnow and hook out of its mouth, and invariably escape.

When a bass strikes, the effect is just the same as if a weight were suddenly tied on the end of one's line, and then, about five seconds afterwards, another heavier weight were added and then removed. 
The sensation is that of a steady pull, and not a series of jerks, as in the case of many other fish such as the rock bass, perch, sunfish and pickerel.

When angling with frogs, similar precautions must be taken to ensure capture.

The hook, which should not be more than an inch in length, is passed first through the under jaw and then through the upper jaw of the frog, as closely as possible to the edge of

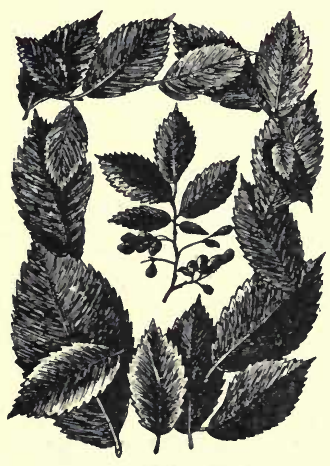

Rock Elm the mouth, and the frog is thus able to swim about quite freely.

When a bass strikes such a bait, it will generally close its jaws on the frog's head just as in the case of the minnow, and then, shortly afterwards, turn the bait around in its mouth by a quick, indescribable movement; and the hook and the frog enter the mouth of the bass together.

But the chance of losing a frog is much greater than that of losing a minnow, on account of the much greater width of the frog's headandits peculiar shape.

It requires much greater skill, therefore, to be successful when using frogs as bait than when angling with minnows or worms.

And the larger the frog, the less the chance of getting the fish.

The only safe rule to follow is to give the fish plenty of time to get the bait well down his throat and trust to experience. With a light rod and small tackle and bait one soon learns to seize the opportune moment. But, even under the most favourable circumstances, one can calculate 


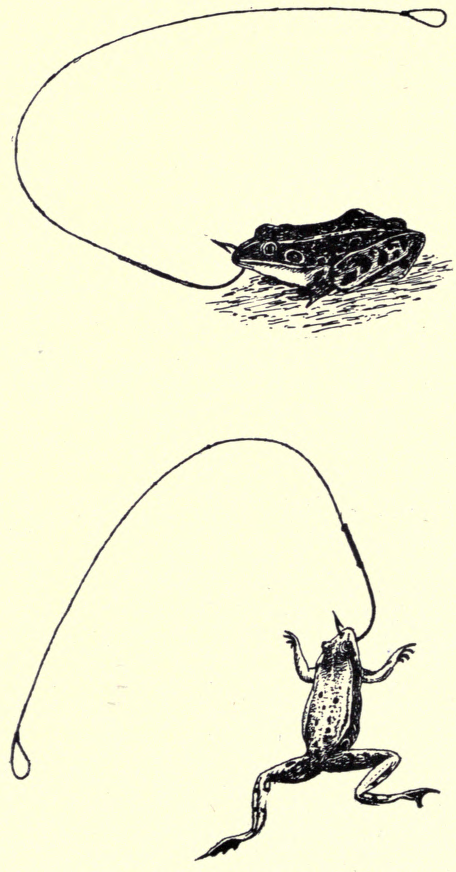

Method of Putting Frog on Hook (Half Natural Size) 
to get not more than about four bass with a dozen frogs, unless the fish are very large and are biting freely.

Only once have I succeeded in getting as many bass as I had frogs; but, in this case, the fish were ravenously hungry, and all conditions favourable: the frogs were very small, and there were no rock bass in the vicinity to strip them from my hook. I was lucky enough to catch ten bass with nine frogs.

Another time, in 1878, on Four-mile Lake near Coboconk, I took twenty-seven bass with thirty-six frogs, in less than an hour; but at that date this lake was alive with bass, and it was no uncommon feat to catch two or three hundred bass in a single afternoon.

But, tempora mutantur: such occasions now are few and far between; and the chance is that the beginner will probably spend an hour in catching a dozen frogs and then lose them all in about ten minutes and be thankful if he succeeds in capturing two or three bass.

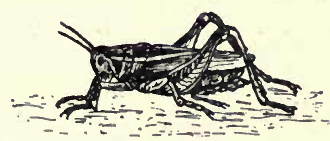

Green Grasshopper

In angling with frogs, the greatest nuisance is the rock bass, which is at times as voracious as the pike, and will attack a frog of any size and mangle it to such an extent that it becomes useless as a bait. Under such circumstances there is only one course open to the angler, unless he happens to have a change of bait, and that is to seek new fishing grounds.

In running streams, especially where there are shallow places filled with broken stone, casting with natural or artificial flies is a most fascinating, but at the same time a most uncertain, mode of angling, on account of the diffculty of keeping the natural bait alive, and, when using artificial flies, of imitating the attractive motions of Nature.

I have never had much success when angling for the 
small-mouthed bass with artificial flies, although I know by experience that his large-mouthed relation will take almost any kind of fly with avidity. I can recommend, however, to those who are fond of this form of recreation, the grasshopper known as the Katydid, which is of a beautiful green

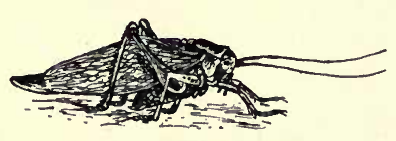

Katydid colour, with delicate wings, and a most attractive bait in bright weather, when angling for the smallmouthed bass in shallow water.

In casting with grasshoppers, or other flies or insects, care must be taken not to damage the bait by passing the point of the barb through a vital part; the bait should be lashed to the hook with fine silk thread in such a way as to allow freedon of motion both of the legs and wings and preserve as far as possible the natural appearance of the insect; for the slightest damage to the bait at once renders it ineffective.

For the angler of mediocre ability, who spends a holiday occasionally in the attempt to secure a few fish for his breakfast, or for the small boy who has been presented with a new rod and line and is anxious to take a few elementary lessons in the art of bass fishing, the humble worm is the best of all baits, and one that may be procured with the least labour.

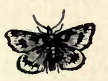

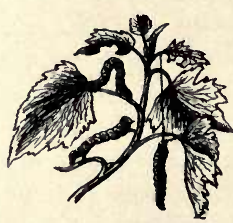

Span-worms and Moth

Of the different kinds of worms, that known as the dew or lob-worm is the most effective for bass. It is found on well-kept lawns or under leaves or boards where the soil is rich. It varies from four to six inches in length.

In using it for angling, a hook about two inches in length is desirable, on which the worm may be run in various ways, 
according to the fancy of the angler and the nature of the fishing grounds. Isaak Walton gives the following instructions in his "Compleat Angler," for the proper baiting of a hook with a dew or lob-worm:

"Put your hook into him somewhat above the middle, and out again a little below the middle; having so done, draw your worm above

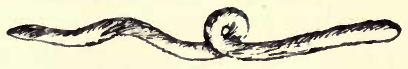

Dung-worm

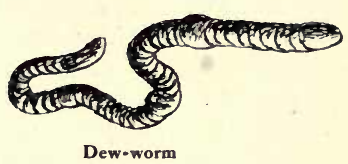
the arming of the hook; but note that at the entering of your hook it must not be at the head-end of the worm but at the tail-end of him, that the point of your hook may come out toward the head-end, and having drawn him above the arming of your hook, then put the point of the hook again into the very head of the worm, till it come near to the place where the point of the hook first came out; and then draw back that part of the worm that was above the shank or arming of your hook, and so fish with it."

Walton gives this method for the

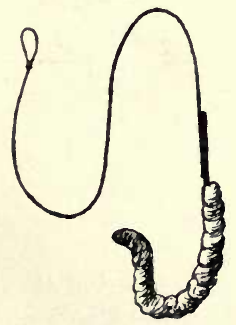
benefit of those who may fish along the banks of a stream or in any place where the water is shallow and the bottom is strewn with branches, logs, or rough stone, and where, consequently, the worm is liable to breakage at the point if threaded in the ordinary way, beginning at the head and leaving about an inch of the tail hanging from the point.

This latter way of baiting is objectionable, even in deep water, because the weight of the free portion and its constant motion gradually cause a break at the point; which, although 
seemingly of small importance from the angler's point of view, is a fatal defect, as the bass has exceedingly keen vision, and as soon as it sees the point of a hook becomes frightened and swims away.

Walton's method, although it prevents the worm from being broken at the point, is open to the objection that the tail of the worm is liable to be snapped off by some small fish; the natural appearance of the bait being thus destroyed; but, if the point of the barb be entered, not at the very end of the head but about an inch from it, then the head of the worm will be placed in juxtaposition with the barb of the hook and the worm may be drawn along uneven ground without danger of being broken at the point.

When a worm is too long to put on the hook entire, it should be cut in two and threaded on the hook by starting at the severed end, thus leaving the head or tail portion close to the barb. In the case where small earth-worms are used as bait, two are necessary, and should be threaded on the hook according to the following scheme given in the "Compleat Angler," and no doubt due originally to Walton:

"You are first to run the point of your hook in at the very head of your first worm, and so down through his body till he be past the knot, and then let it out, and strip the worm above the arming (that you may not bruise it with your fingers) till you have put on the other, by running the point of the hook in below the knot, upwards through his body towards his head, till it be just covered with the head; which being done, you are then to slip the first worm down over the arming again, till the knots of both worms meet together."

This arrangement is likewise open to the objection that the tail of the worm on the shank is liable to be bitten off first; although the fish will then, as a rule, proceed to attack the tail end of the other worm lying near the barb and doubtless be hooked. 
Dung-worms, used in this way, give excellent results, but only with a very small hook, not more than an inch in length.

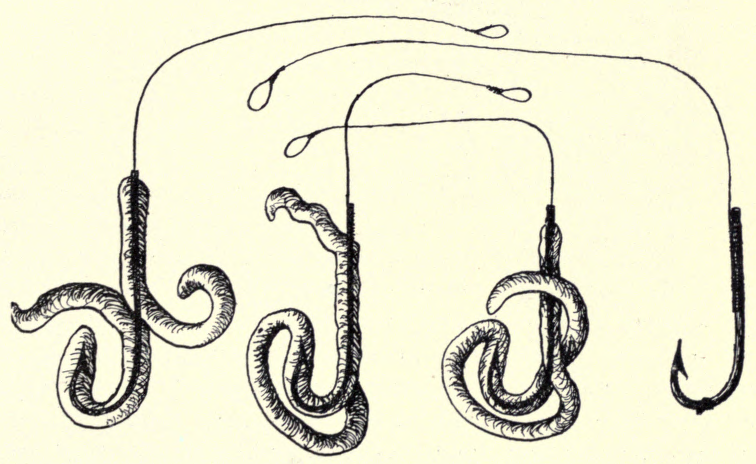




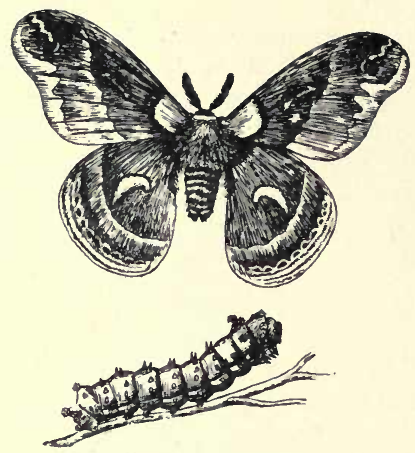

Silk Moth and Larva

\section{CHAPTER VI.}

BAIT:

$\mathrm{N}$ the pursuit of the small-mouthed bass the veteran angler pays particular attention to the question of bait; and it will be well for the beginner to devote some time to a consideration of the different methods of procuring it, as well as to its preservation, especially during periods of very hot weather, when bass are usually most active and bait is so difficult to obtain.

First in order comes the worm, which is, of all baits, the most commonly used, and the most easily procured. Of the different varieties the most effective is the large dewworm, which is found at night time, after a hot day, on lawns that have been well watered towards sundown; one may, with the aid of a lantern, easily pick one hundred of them in an hour. The worms evidently emerge from the ground at night to seek the moisture on the surface, and as they 
crawl from their holes they may be seized and captured, although it requires some practice to take them, and one must be quick in laying hold of them to prevent their sudden withdrawal into their holes.

If a lawn be not available, they may be found under planks or rotten logs where the earth is rich in clay.

Worms dug from earth are not usually as large or as lively as those taken from grassy places, but sometimes very good specimens may be dug up with a spade from rich earth.

Dung-worms are found in rotten dung heaps, especially when the dung has been mixed with leaves and the process of decay is well advanced. The best kind is about two inches in length, of a reddish-brown colour, with black rings running around the body, and very lively.

To preserve worms in a proper state for angling, particularly in very hot, moist weather, requires some degree of attention.

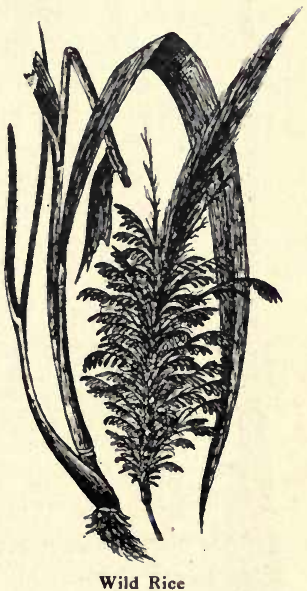

They should be placed in shallow boxes, with two or three inches of earth, and a top layer of soft green moss, which, if not available, may be replaced by grass; but, in this case, the grass must be renewed every day, as it rots quickly, and thereby destroys the worms.

A box, four by six by eight inches, made of half-inch or inch pine, so that it will not warp or split, having a cover filled with air holes and furnished with two hooks and eyes so that it may be fastened down securely, is the most satisfactory form; such a box will hold one hundred worms. 
The air holes in the cover should not be more than oneeighth of an inch in diameter, and the cover should fit flush with the box; otherwise the worms will stretch themselves through and escape.

The boxes containing the worms should be kept in a cool place, of a temperature not greater than $50^{\circ} \mathrm{F}$., and, if possible, where there is a free draught of air.

In the heat of summer it is difficult to fulfil these conditions; and, unless one has access to an icehouse, worms cannot be kept, during very hot weather, for a much longer period than a week, in a proper condition for angling.

But if an icehouse be available they may be kept for months by simply placing the boxes on a bare piece of ice; this enables the worms to get the moisture necessary for their development, and at the same time to keep cool.

When this method is employed there should not be more than fifty worms in a box, and they should be inspected once a week or more frequently, and any dead ones removed.

Green moss, such as one finds along the edge of a marsh, should be used for a top dressing, because it retains moisture, and enables the worms to scour themselves and thus become tough and lively, and

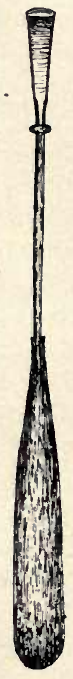

therefore less liable to break when placed on a hook. Any kind of moss is much better than grass.

Larger boxes may be used for preserving a great number of worms, but they are more difficult to handle, and the chances are that the worms will all collect in one corner of the box, and more will then be lost by decay. The smaller 
boxes are more easily inspected, and the loss by decay in them very much less.

For the preservation of frogs, crayfish, grasshoppers, etc., a box with a wire netting is desirable. It should be made of inch pine, six by six by eighteen inches, provided with a lid and an opening for the hand, which can be covered securely by a wooden shutter working on a pivot. The box should have also a handle on the top of the lid, the latter being held tight to the top by means of two hooks and eyes; the front of the box being covered with brass or copper gauze with one-eighth inch mesh.

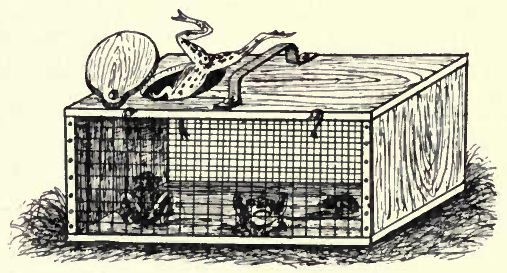

Frog Box

The whole should be put together with brass screws, hooks and hinges; this insures that there will be no rust, and the box will then last a lifetime.

Damp moss placed in the cage will keeps frogs alive for weeks, especially if they are exposed to the sun for the greater portion of the day. The moss should be renewed at least once a week.

If grasshoppers are to be kept longer than a week, small green leaves should be given to them, those of the wild cherry being the best, unless lettuce leaves can be obtained in a fresh state; these form the best food for grasshoppers in confinement.

Crayfish, crickets, and almost all varieties of insect bait 
may be kept in such a box as has been described for weeks at a time, if fresh moss from the edge of stagnant pools be put in occasionally; this usually contains sufficient nourishment in the form of water and organic matter to provide food for the prisoners.

To keep minnows alive is perhaps the most difficult task of the angler, particularly when the temperature of the air rises above $80^{\circ} \mathrm{F}$, and access cannot be had to running water. Minnow pails of various kinds may be used, but as they are usually made of iron plate, coated with tin
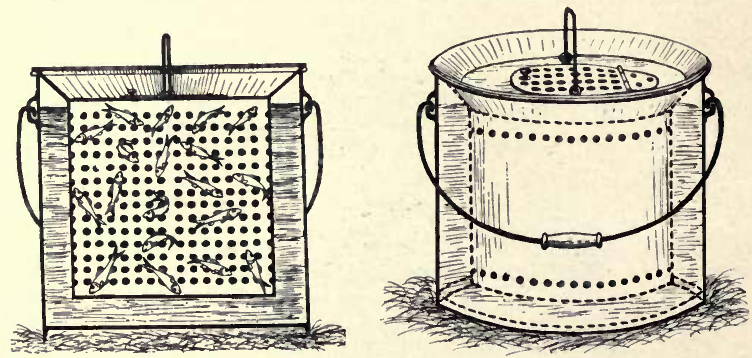

Minnow Pail

or zinc, they are more or less rough, especially in the neighbourhood of the perforations, and thus delicate minnows, like the silver shiner, by constant rubbing themselves against the sides, become deprived of their scales and soon die.

After much experimenting with all kinds of minnow pails, I have abandoned them for the common wooden pail, covered with a double layer of cheese cloth, thoroughly washed and bleached and kept constantly moistened with water.

The pail should be an old one, which has been well worn inside so as to present a smooth surface. If the weather be very hot and the minnows have to be carried a long distance 
exposed to the direct rays of the sun, the pail may be placed inside a larger one and the space between the two filled with ice, and a second double layer of cheese cloth placed over the top of the outer pail; the whole forming a perfect nonconductor of heat, while the evaporation from the cheese cloth assists in keeping the temperature reduced to a minimum. With such an arrangement minnows may be carried about in an open boat for a whole afternoon in summer without losing any of their vitality, provided a few cups of water be occasionally dipped out and fresh water poured in from a height of three or four feet, so as to produce aëration of the water in the pail.

When the temperature of the air rises above $80^{\circ} \mathrm{F}$. it becomes a difficult matter to keep delicate minnows like the shiner from day to day. The method I have employed is to take a large perforated tin can, about two feet in depth and one foot in diameter, with a tin cover; such a pail as in fact is used for the ordinary transportation of minnows, and then attach to the top, but so as to clear the cover, a piece of wood about eighteen inches square and two inches thick, with a circular hole, into which the pail is fastened tightly. This may be filled with minnows, and the whole arrangement placed in deep water, if possible where there is a current, and tied to some object on shore to prevent it floating away. The buoyancy of the wood will keep the tin erect, and when one wishes minnows they may be taken out from the top by means of a small dip-net, with a handle about a foot long. All the various kinds of submerged-boxes made of wire netting are not of much use, as the minnows rub themselves constantly against the meshes and wear off their scales.

The labour of capturing minnows, frogs, grasshoppers and other insects is almost as great as that of taking bass.

For grasshoppers and moths, if a small butterfly-net is used, a dozen or two may be taken in an hour; but with frogs, which always haunt the edge of a pond or stream and 
dive into weeds and slime when pursued, the problem of capture is quite different.

The first essential in getting frogs is a pair of rubber

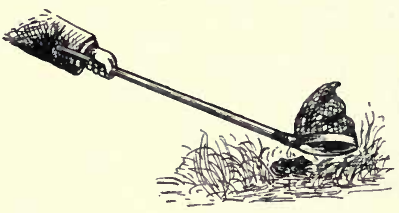
boots, reaching to the hip, so that one may wade along the shore, well out in the water, and chase the frogs to the shore.

In addition, on e should have a frog-net, with a handle about two or three feet in length, made in such a way that the frame of the net is inclined at an obtuse angle to the handle, and having a covering of some flexible material like mosquito-netting. One may then catch a dozen frogs in an hour, if they are not very plentiful, and two or three dozen if they are in abundance.

The frog-net is made of a piece of bamboo rod, with a waxed cord wound around one end so as to provide a suitable handle, and a loop to hang it up.

A brass wire about one-eighth of an inch or three-sixteenths of an inch in diameter is bent into the form of a circle, and the ends filed down flat so as to fit the other end of the rod, to which it is lashed with brass or copper wire.

This ring should then be bent into the proper position, so that it makes a slight angle with the prolongation of the rod, about fifteen or twenty degrees; and mosquito-

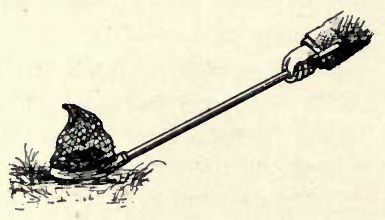
netting is sewn carefully on the ring so as to form a conical bag about eight inches in height.

The netting soon wears away, as it is very delicate; but 



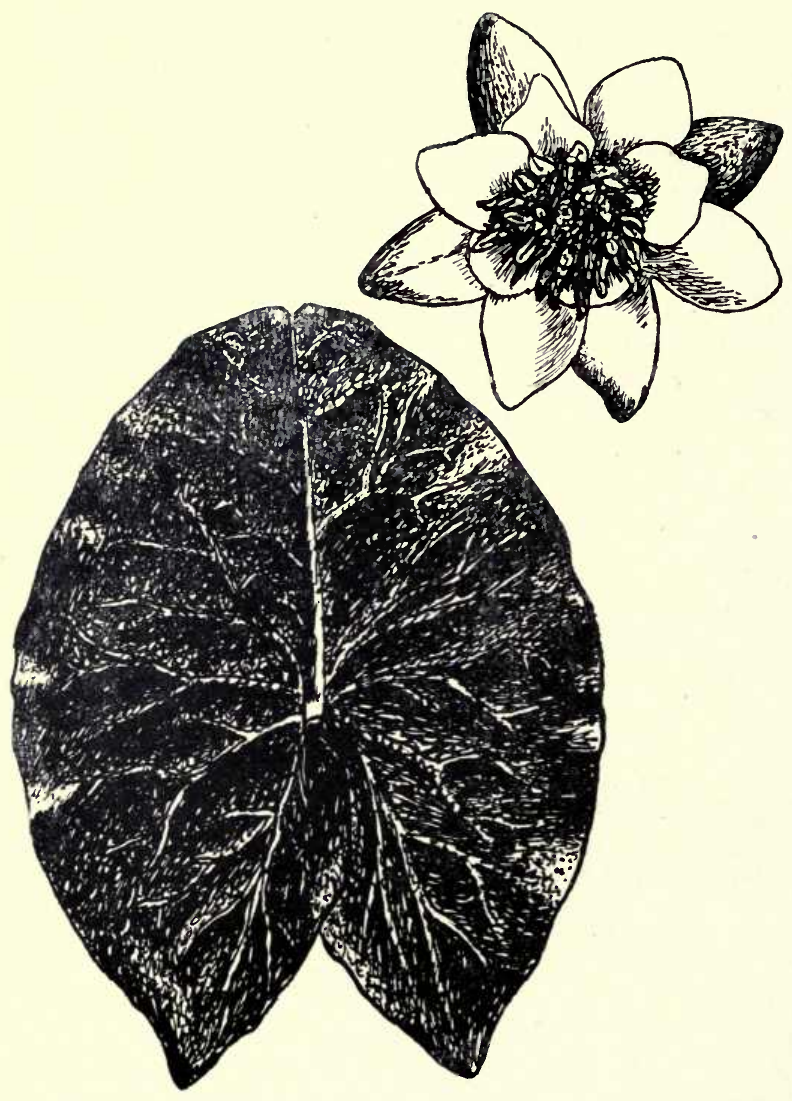


may be replaced in a few minutes by new material. A very small hole will allow the frog to escape.

The reason for the bending of the ring, so as to form an angle with the handle, is that one can, without reaching down too low, clap the ring and net flat against the ground, a thing which cannot very easily be done if the handle lies in the plane of the ring.

The ordinary net used for landing fish is of no use to catch frogs, as the handle is too long and the net has too large a mesh.

Iron or copper netting should not be used for a frog-net, because, although it is durable and lasting, it does not permit one to grasp the frog while the ring is against the ground, and three times out of four one will lose his frog in attempting to get it from under the ring. In addition, there is also the danger of injuring the frog by striking it with the metallic netting.

With mosquito-netting, the frog, as soon as he is covered, jumps up, becomes entangled in the netting, and at once works his way to the apex of the cone-shaped bag, where it may be easily seized from outside along with the netting, and dropped into the frog box, without chance of injury. Usually one can find frogs in shallow, marshy places, where there is a sand beach, during the summer months of July and August.

It is difficult to find them in spring or fall, or in cool weather, as they seem to dislike a temperature below $70^{\circ}$ or $80^{\circ} \mathrm{F}$., and when the days are cool, hide in the mud or crawl under stones.

It is almost as laborious to catch frogs on any given day as to take bass; for they are easily frightened and, after . being once chased, become exceedingly wary.

Crayfish, which may sometimes be used as bait, especially if they be small and tender, are caught by wading along the edge of a shore which is strewn with broken rock. On rais- 
ing the stones gently, so as to prevent clouds of mud from rising and obscuring the view, numbers of these animals will be seen scuttling away in all directions, but it requires some skill and practice to seize them, even when using a small dip-net.

The best way to obtain them in any quantity is to take a wooden box with a number of inch augur holes bored in its side, place it in the water, loaded down with small pieces of broken stone, and put in small pieces of refuse of any kind, - such as the heads or entrails of fish. If left over night such a box will be found next morning filled with crayfish. It should then be lifted out quickly on shore and dumped on an open space, where the crayfish may be easily captured. For minnows, a small seine may be used, twenty or thirty feet long, if large quantities are desired; this, however, require two or three men and a boat, if the water be deep, and also some experience.

For the beginner, the easiest way to get minnows is to use a rod, line, and the smallest minnow hook available, from an eighth to a quarter of an inch in length, and bait the hook with a minute fragment of a dung-worm, the head being the best part. One may catch two or three dozen minnows in this way in an hour, and most of them will be uninjured by the hook.

Anchor a boat over a weed-bed where the water is about six feet in depth, and stir up the mud at the bottom with a paddle or oar; this causes a great number of food particles to hang suspended in the water and attracts minnows from the surrounding vicinity; when the water becomes clear one has no difficulty in catching small perch and minnows.

Sometimes minnows swim about in large shoals, and in that case a large dip-net may be used. This is made of a wooden hoop, three feet or more in diameter, with a piece of mosquito-netting sewn to the hoop in the form of a very flat cone, so as to bag down about eight inches or a foot. 
The net is then twisted at the centre and tied with a cord to which a small weight is attached, so as to keep the bag in position when placed in the water.

A pole, eight or ten feet in length, made of pine or cedar, light and strong, is then fastened to the hoop, so that a portion of the end of the pole forms a diameter of the hoop.

Then one proceeds to a place, in six feet of water, where minnows congregate, and the net is sunk to the bottom. If particles of dry bread or oatmeal are then thrown in the water, immediately over the spot where the net is sunk, the fish soon appear and begin to feed on the fragments which have been thrown in; as soon as a sufficiently large number are over the net, it is lifted suddenly and sometimes two or three dozen minnows may be caught in one haul.

But care is required, and, if the water is very clear and the sun shining brightly, the fish will escape before the net reaches the top of the water, unless the operation is performed very suddenly.

Various other contrivances, in the form of traps, are made to catch minnows, but they all require special attention, and are apt to get out of order; for the ordinary angler the best way to secure minnows is with the minnow hook and a small fragment of worm.

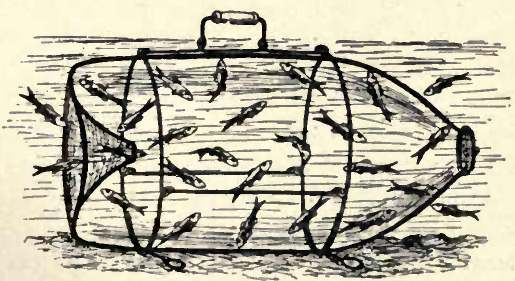

Minnow Bottle Trap 


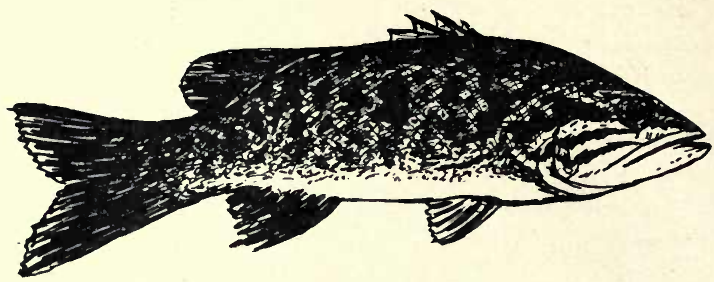

Bass Spawning

CHAPTER VII.

\section{Propagation.}

Spawning.

THE spawning season is in the spring of the year, but

1 varies with climatic conditions, as well as with the temperature of the water; and, although cases are recorded of propagation taking place during the summer or even in the early autumn, yet the general law is that, as soon as winter is over and the sun begins to warm the water, the male and female bass "run" in large shoals, and proceed to choose a suitable place for the important function of spawning.

It is now a well-established fact that the male bass prepares the nest or spawning bed, usually on coarse sand or gravel in a protected spot close to shore, and preferably where the water deepens suddenly, so that the nest is on a sort of ledge, from which the fish may make observations in all directions.

Sometimes he chooses a ledge of rock in two or three feet of running water, one side of which is close to shore and forms a little bay, while the other side is bounded by water 
eight or ten feet in depth; this gives him complete command of the situation, and enables him to drive off his enemies with ease.

When first seen the male fish roots about in the sand and clears away, with his fins and tail, a spot about two or three feet in diameter, so that the bottom is either of bare rock or strewn with coarse stone and gravel. If the nest be made on rock he sweeps off the dirt and slime until the surface of the bed is perfectly rough and clean.

Then, suddenly, some fine sunny morning, when the temperature of the air is between $70^{\circ}$ and $80^{\circ} \mathrm{F}$., and that of the water about $65^{\circ} \mathrm{F}$., he appears with his mate, and, after circling about in the nest for a few minutes, the female deposits her ova, which are immediately covered by the milt of the male fish, and the female then either abandons the nest of her own accord, or is driven from it by the male, who then proceeds to "guard the nest."

While spawning the female undergoes a remarkable change in colour, and becomes mottled in the same manner as when affected by a sudden change of light or heat.

\section{Guarding the Nest.}

This process is one of the most interesting and instructive in Nature, and is not peculiar to the small-mouthed bass, being carried on by the large-mouthed bass, the rock bass, and some species of sunfish; perhaps also by the maskinonge.

The male fish remains over the bed and guards it until the ova are hatched out, and the young bass are ready to leave the nest.

He keeps moving about over the nest, or remains with his head at the centre while his tail sweeps the water in a circle; or occasionally he rushes out to chase away some wandering fish, either of his own or of other species, returning immediately to his station. 
$\mathrm{He}$ is a fearless guardian, and is not very easily driven from the nest, even by man.

This guarding process occupies a week or ten days, or in some cases a much longer time, all depending on the temperature of the air and water and the action of local currents, which aid aëration.

During this period they apparently take no food, although in several cases, after the lapse of a week, I have caught them with minnows, and thereby satisfied myself that the male fish guarded the nest. In no case have I ever caught a female small-mouthed bass or rock bass guarding a spawning bed; it was always the male who was acting as guardian.

The young fry when first hatched out are very small, probably about half an inch in length; and they usually remain in the vicinity of their nest, still guarded by the male, who herds them close to shore while he swims to and fro on the outside so as to protect them from enemies. Then in a few days they gradually disappear, and may be seen subsequently swimming about in detached shcals in search of food. The most exact and careful scientific observations on the spawning habits of the bass have been made by Mr. Dwight Lydell, of the Mill Creek hatchery, of the State of Michigan, an account of which is given in Bulletin of the Michigan Fish Commission, No. 7, by Dr. Jacob Reighard, of the University of Michigan. I reproduce here some of the most interesting statements from this report.

Nests and Nest Building.-The small-mouthed black bass (Micropterus dolomieu) makes its nest by preference on coarse gravel. From the end of April until the end of June, the time depending on the latitude and the temperature of the water, the male fish make their appearance in shallow water and may be seen moving about in search of suitable nesting places. The male then frequently puts his snout to the bottom and roots as though to test for the presence of 
gravel. One may often see in breeding ponds places that have been thus tested. They may be no more than four or five inches across, or may be irregular linear patches several feet long, and in such spots the gravel is exposed, while all about them it is hidden under a smooth layer of sediment. When he has found a suitable place the male takes a vertical position in the water, head up, and by a powerful sweeping movement of the tail he removes from an area two or three feet across the sediment which covers the gravel. When this occurs in a stream, the sediment, carried down by the current, settles to the bottom below the nest. In ponds where there is no current the sediment is not carried down and the water over the nest becomes consequently so much rolled during the sweeping that the fish frequently is forced to leave the nest until the water has become clear again. The sweeping clean of the gravel is the first stage in the building. The nest is

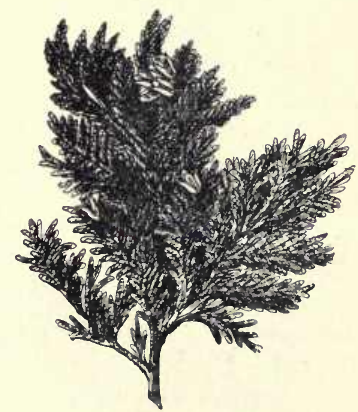

White Cedar then said to be "cleaned up," but is not yet completed. The fish next stands on its head, roots over the gravel, more particularly at the centre of the nest, and then resumes sweeping with his tail. He thus alternately roots and sweeps until all the sand and smaller stones are swept to the edge of the nest, leaving only the larger stones at the centre. This removal of material from the centre of the nest and its accumulation at the border leaves the nest saucer-shaped. At the centre the sand and fine gravel is removed, not merely from the upper surface of the stones, but between them to a considerable depth, so that the crevices between the stones 
are free from it. The stones are made perfectly clean by the sweeping process and have the appearance of being polished so that they stand out in conspicuous contrast to the sediment-covered stones surrounding them. This "hollowing out" of the nest is the second stage in its construction and it is now complete.

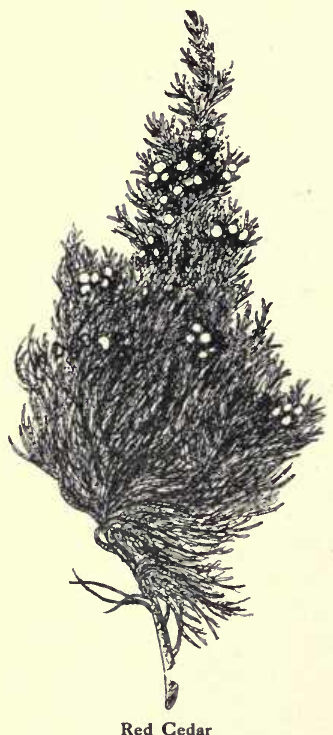

The small-mouthed bass not only seeks a gravel bottom of a certain coarseness for the preparation of his nest, but he places it, if possible, in a sheltered situation. Of fifteen nests examined in the Thornapple River at Cascade, Michigan, all but one was built either near the river bank or near a large boulder or log. These nests were thus protected from intrusion on at least one side. That such sheltered spots are selected for nests is further shown by the fact that in breeding ponds where sheltered nests are provided, the fish almost invariably use these instead of using gravel which may have been placed for their use in unsheltered situations. Indeed the fish will sometimes use sheltered nests which have been placed in ponds for large-mouthed bass and the bottoms of which are made of the fibrous Spanish moss imbedded in cement. Thus a sheltered situation appears at times to be a factor more important than the nature of the bottom in determining the location of the nest. The nests that I have seen in natural waters were all located where there was a current. 
Guarding the Empty Nest.-When the nest has been prepared the male remains on guard over it, but makes frequent circles into deeper water as though in search of the female. The time between the completion of the nest and the actual spawning may be but a few minutes, as in one case that I observed, or it may be some days. The length of the interval depends, in part at least, upon the temperature. The males may begin nest building in a temperature somewhat below 60 degrees F., but the females do not spawn until the water has reached a temperature of between 62 degrees and 65 degrees $F$. If the male does not begin nest building until the water has reached 62 degrees F., the spawning may follow at once upon the nest building. If the male begins the nest when the water is below 60 degrees F., spawning is delayed until the weather conditions have brought the temperature of the water to a suitable point.

Spawning.-After the male has guarded the nest for a time he returns from one of his excursions into deeper water, accompanied by the female. At most seasons there appears to be no external difference between the sexes, so that it is impossible to distinguish them without dissection. At the breeding time there is ordinarily no difficulty. The females are then much thicker bodied and, particularly when seen from behind and somewhat from above, may be distinguished from the males by the form of the body, even at a distance of from ten to twenty feet. Small females sometimes spawn when they contain very few eggs and these of small size. It is then not easy to distinguish the sexes by the form of the body alone, and if there were no other method mistakes might easily be made. But in all cases the behaviour of the two sexes is so wholly different that the person who has once observed it in a case where the sexes were easily distinguishable by the form, need not afterward hesitate to distinguish the sexes at the spawning time by their behaviour alone. In addition to difference in form and behaviour, a marked differ- 
ence in colour between male and female nearly always becomes evident as spawning proceeds. From a knowledge of these differences between the sexes at this season there can be no doubt of the correctness of the statement that the fish which brilds the nest and which subsequently guards the eggs and the young fish is the male. As further evidence of this, on five different occasions the fish which was guarding the nest of the young brood has been taken on the hook and on each occasion has been found upon dissection to be a male.

Although I have seen the small-mouthed bass on their nests probably hundreds of times and have four times observed the spawning in part, and once throughout its whole duration, yet I have never seen a female on or near a nest except when actually engaged in spawning.

The following account of the spawning is from field notes of the case in which the whole process was observed. The other four cases in which the spawning was observed in part did not differ in any essential way from this one. "On May 11 th, at 12.30 p.m., a fresh-built nest is found near the outlet of pond 1. It is in about eight inches of water in the open, that is, not within one of the artificial shelters provided for the nesting fish, and near shore. The male fish is on the nest, the water is clear, there is no wind and the sun is shining. The conditions are therefore ideal for observing the spawning habits. A weather-worn batten-door is hastily obtained, a hole is knocked through it, and it is then propped on edge about ten feet from the nest. Through the opening one may observe the nest with field glasses as clearly as though he held it in the hand."

"The screen is hardly in place before the two fish, each about 10 inches long, are seen, one two yards north of the nest and the other two yards south of it. Both are small fish and at first the sexes can therefore not be distinguished. Presently one of the two approaches the other and urges it into the nest. Both fish are of the usual dark green-bronze 



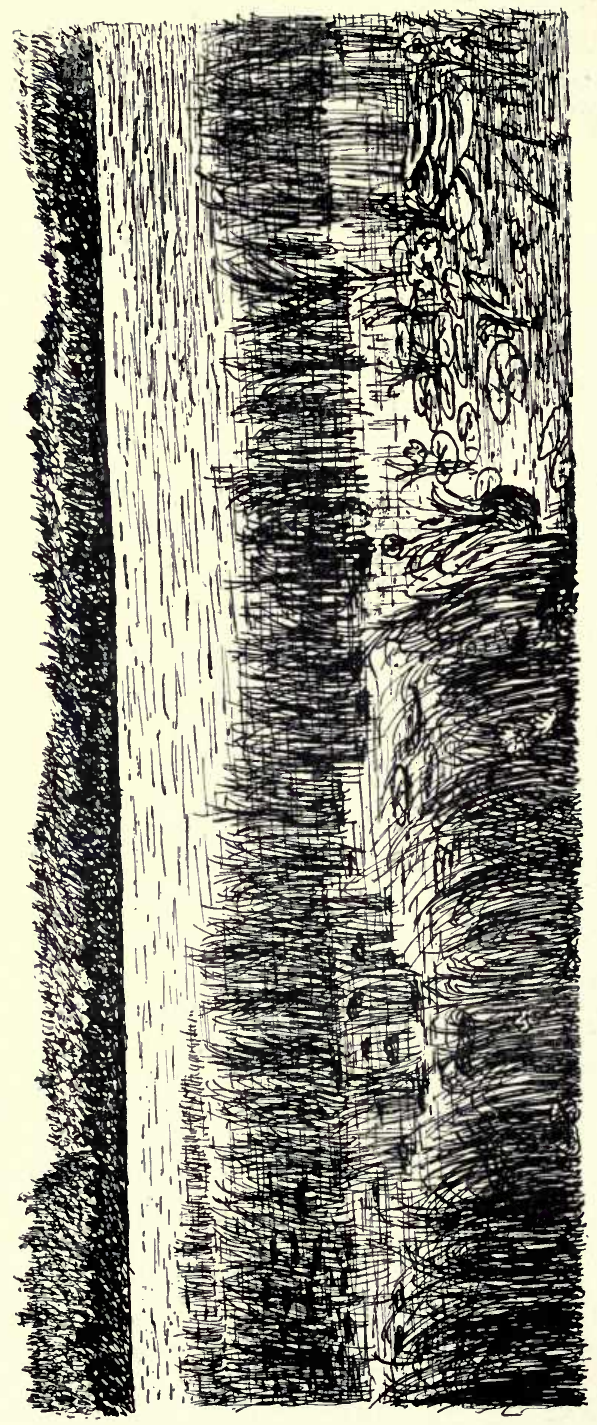


colour and both are apparently uniformly coloured over the body."

"In a few minutes after the fish have entered the nest one of them begins to show dark spots on the sides and at the end of five minutes is sharply mottled over the whole body. (The subsequent behaviour of this fish, as well as the fact, later observed, that it is thicker bodied, showed it to be the female).

"At the angle of the free border of the opercle of the female is a white spot, and above this the caudal end of the stripe through the eye ends in a darker spot. This white spot stands out with great distinctness in this female under sexual excitement, though it is visible at all times in both male and female. It occupies the position of the ear flap in the other sunfishes. The female is but little thicker than the male and (contrary to the usual condition) is lighter coloured. The male is slightly mottled and has the black and white ear spot. The upper and back part

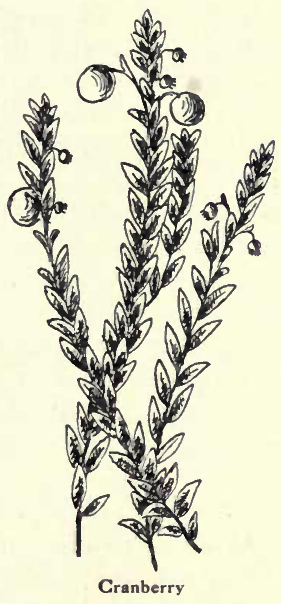
of his eye (iris) is scarlet, while that of the female remains brown, though in other females I have seen the eye temporarily red. The male is then distinguished by his red eyes, more slender form and darker colour. The mottling of the body of the female here described is present at all times in both males and females, but is ordinarily very inconspicuous because the network, in the meshes of which are the darkerspots, is itself almost as dark as the spots. Under sexual excitement this network fades (probably by contraction of its pigment cells) to a light green colour and the darker 
spots enclosed by it are then thrown into strong relief. The fish is then said to be mottled. The mottling takes place not only under sexual excitement, but when the fish is suddenly transferred from warm to cold water. Not only are the spots on the body of the female thus brought out with great distinctness under sexual excitement, but the spots themselves usually become darker. The female under sexual excitement thus appears darker than usual and usually darker than the male."

"While the colour change has been in progress the fish have been moving slowly about over the nest, the male biting the female frequently, though gently, on the opercle, cheek and corner of the mouth. During most of the time the female swims slowly on her side in a circle. Frequently she floats motionless, partly or wholly turned on her side, and at such times the male often lies beside her. Every two or three minutes she takes an upright position and rubs her belly against the stones, while at the same time she moves slowly forward with a deliberate bending of the body first to one side and then to the other."

"Now the female is seen to leave the nest. She goes to a distance of fifteen or twenty feet, but is pursued by the male and brought back. Now two strange males pass and are at once set upon by the male, who drives them off, while the female waits in the nest. One of them returns and enters the nest with the waiting female, but is at once vigorously repelled by her mate."

"At 1.20 (i.e., after 50 minutes) the movements first described are still in progress, but no eggs appear to have been laid. The male is never seen to elevate the gill covers or to pose before the female. When biting her he usually approaches from behind, and lies at her side or below her. Frequently the two stop and lie quiet, side by side, the female turned partly on her side, the male upright. Such 
quiescent intervals last a few seconds and the circling movements are then resumed."

"At 1.30 (i.e., in one hour) egg laying begins. During the emission of eggs the two fish lie side by side on the botton. The female is turned partly on her side so that her median plane forms an angle of about 45 degrees with the plane of the horizon. The male remains upright with his head just back of the pectoral of the female or opposite it. While emitting the eggs the female moves her pectorals alternately and slowly back and forth like oars; at the same time her dorsal is partly depressed and rapidly vibrated. During this time the male lies quiet at the side of the female, but toward the close of the egg laying interval he backs slowly with alternating movements of his pectorals until his snout is opposite her vent. He then usually bites her on the vent, appears to examine the emit-

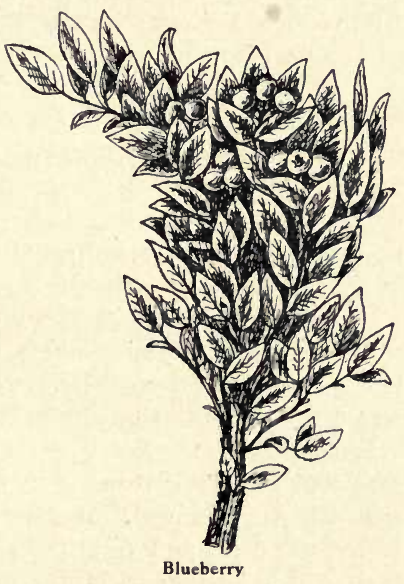
ted eggs and then moves forward and bites her once or twice on the opercle or cheek. Four successive egg laying periods timed with the watch are found to be $4 \mathrm{sec}$; 4.5 sec.; 5.5 sec.; 6 sec."

"Each egg laying period is succeeded by an interval of circling over the nest or just at its edge, but the two fish are now less active. The female especially is more quiet, and no longer rubs her belly on the pebbles. The male moves about somewhat, but less actively than before egg 
laying began. He occasionally bites the female. Since egg laying began the female has become much darker, and is now as dark as the male. Five successive intervals between the egg laying periods timed by the watch are found to be 22 secs.; 28 secs.; 30 secs.; 32 secs.; 45 secs."

"With the aid of a field glass the eggs, it is now thought, may be seen issuing from the oviduct, but this is necessarily uncertain. No milt can be seen, since the milt is colourless. After a time the eggs are clearly seen adhering to the stones of the nest bottom."

"At 2.50 p.m., two hours and twenty minutes after the fish entered the nest, the female leaves it, pursued by the male. The niale, no longer mottled, soon returns and takes up his position over the nest. There he poises and fans the eggs with his pectorals, but frequently goes outside the nest and circles the immediate neighbourhood, as though in search of possible enemies."

I have described this case in detail because it is rare that so good an opportunity offers for observing the spawning behaviour of the bass. Mr. Lydell, who watched with me, was of the opinion that the movements of the fish were less vigorous than in other cases which he had observed, but admitted that he had never had a better opportunity. The eggs laid in this nest, after developing normally for about two days, died, and this I can attribute to no other cause than a lack of vigour on the part of one or both parents. Yet the spawning behaviour of these fish was not seen to be in any way different from that of the four other pairs that were observed in a fragmentary way.

In another case in which the spawning was watched the female twice attempted to leave the nest, but was each time pursued by the male, who took up a position outside of her and bit her in such a way as to drive her into the nest. At the third attempt she escaped and was not seen to return. 
Since the male exanines the eggs after each act of emission, he is in a position to know when the female has finished laying, and it is then apparently that he drives her from the nest.

That a female may spawn in more than one nest is shown by the following observations:- "On the south side of pond No. 5, about eight feet from shore, I found a nest in which were a male and a female, easily distinguishable as such at a distance of fifteen feet. The male was lighter coloured and was mottled; the female was darker, more mottled and plainly distended with eggs. There was the same swimming and floating in a circle on the side on the part of the female and the same biting on the part of the male that has already been described. This was interrupted by periods during which the fish lay on the centre of the nest where they could not be plainly seen. At these times eggs were doubtless emitted. Presently the male apparently saw me and swam away with a start, as though frightened. The female remained waiting and appeared to become gradually lighter coloured. After five minutes she also started away, but she was met by the

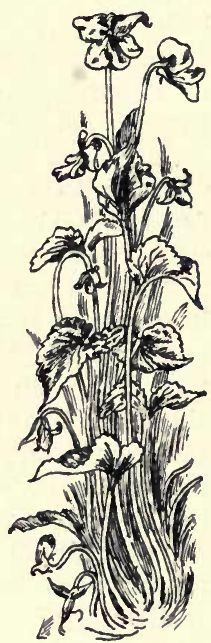

Marsh Violets male and, as she attempted to leave the nest, was headed off first on one side and then on the other, until finally she was brought again into the nest."

"In a short time the male was again frightened away and again the female remained in the nest. The male did not at once return, but remained circling about a neighbouring nest situated at a distance of about fifteen feet from the original nest. At intervals he approached his own nest, coming 
nearer each time. After ten or fifteen minutes the female also started to leave the nest. The male then headed her off and brought her back. He was soon again frightened and both fish then went to the adjacent nest, about which the male had been circling, and there renewed the spawning activities. Both fish were still in the nest at the end of an hour."

In still another case:- "On May 9th a male and a female were seen together in a nest. The female left the nest and the male followed. In her flight she passed a second nest on which was a large male. He also pursued the female and after a minute or so succeeded in getting her away from the first male and took her into his own nest." Both nests were subsequently found to have eggs in them.

That a single male may receive into his nest two females in succession and guard their eggs is shown by an experience in one of the breeding ponds at the Mill Creek hatchery. "This small pond contained a single male, easily distinguishable from all other fish in the pond by his size and by a black spot on one side of his head. He was very tame and it was the practice of the employees to feed him frequently. Whenever a stray frog, grasshopper or crawfish was picked up it was carried and thrown in to him. During the season this fish reared on one nest two different broods of young."

Care of the Eggs and Fry.-The male remains over the nest and by alternating movements of his pectoral fins, as well as by a vibrating movement of his caudal, executed either while he is poised over the nest or while he swims slowly across it, he gently fans the eggs and thus in a measure keeps them free from sediment. At frequent intervals he leaves the nest and circles close about it, now in this direction and now in that. Again he makes wide circles into the neighbouring territory, as though to assure himself that no enemies are present. $\mathrm{He}$ is not easily frightened from the nest. As one approaches the nest at this time, if the male 



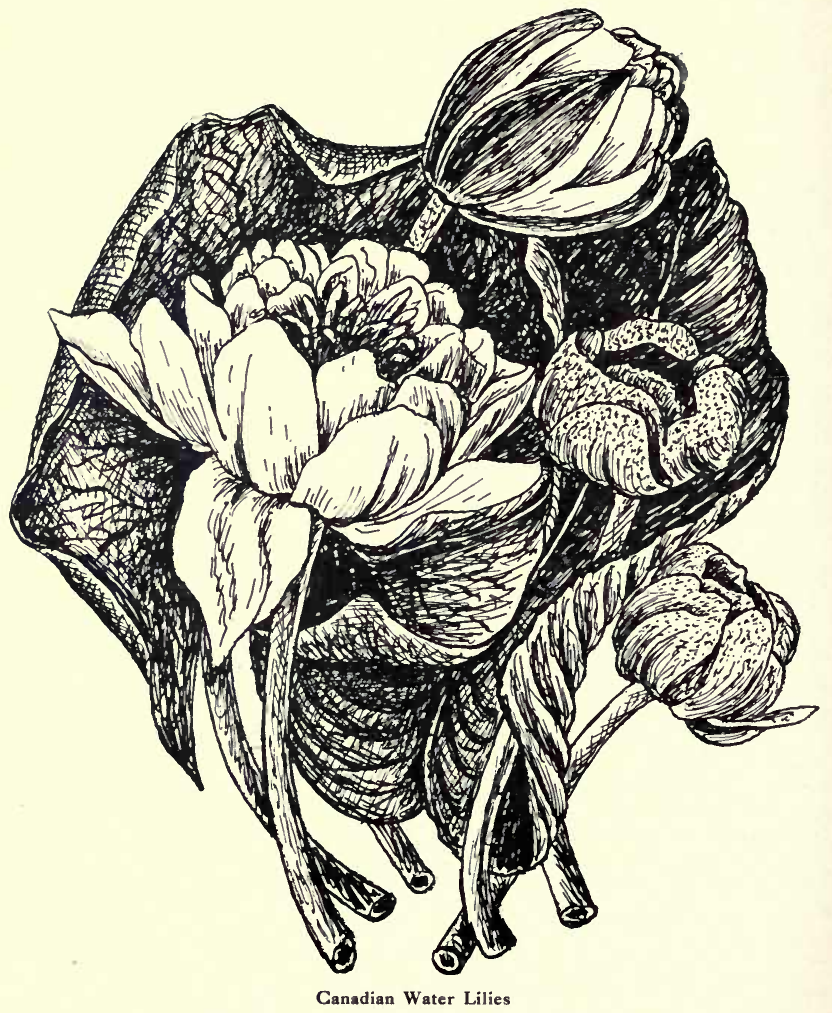


remains near, it will nearly always be found that the nest contains eggs or young fish. One may sometimes approach the nest and introduce the hand into it before the male takes flight. If the male leaves at once and hurriedly, as the nest is approached, it will usually be found to be empty.

If another fish approaches the nest at this time he is invariably attacked and driven away. I have never seen other fish stop to do battle at this time. They invariably flee, as though recognizing the ability of the brooding fish to successfully defend the nest. Although the presence of the male fish thus keeps the eggs in a measure free from sediment, it does not effect this completely. After a time the fry, newly hatched, fall into the crevices between the pebbles, where they may be seen only with the greatest difficulty. The pebbles in a freshly made nest are scoured clean and the nest is thus rendered conspicuous, owing to the fact that the nest pebbles, with their coating of eggs, stand out in sharp contrast to the sediment-covered pebbles of the surrounding bottom. With the lapse of time the sediment gradually accumulates in the nest in spite of the movenients of the male, which must not be too violent lest the loosely attached eggs or the helpless young fish be swept from the nest. The result is that by the time the eggs have hatched the nest is no longer conspicuous. He who would now find it, should search not for the nest itself but for the male that guards it. If a male bass is found, not readily frightened away at the sight of the observer, and if the frightened fish returns after a time to the same spot, a nest may be sought for in the neighbourhood. A careful examination of the bottom may then show a depression in which the pebbles are less thickly covered with sediment than elsewhere. Such a nest may, however, have been so nearly obliterated by the deposit of sediment that it is only when one brings up the eggs or young fish from the bottom with a dipping tube that one may be sure of it. 
The pertirnacity with which the small-mouthed bass guards his nest is often conspicuous in breeding ponds. Here it is the custom, as described in another part of this paper, to surround the nest by a cylindrical screen shortly before the young fish are ready to leave it. The parent fish is excluded from the screen, while the young fry confined within it are kept from scattering and may be readily had when needed for shipment. The male fish now returns to the nest after a little while and remains on guard outside the screen. It is usual to see the screens thus guarded. In one case an individual male was seen to continue guarding his screen, swimming continually in a circle about it for six days. During this time he was repeatedly seen attempting to enter the screen by burrowing beneath it and by butting it again and again with his head.

When the eggs are hatched the young fish remain for some days on the nest and then leave it, accompanied and guarded by the male. The school of young fish now usually seeks shallow water and may be found along shore. Here the parent fish swims back and forth in a half circle outside his school. This care of the school by the male is continued until the young fish are from an inch to an inch and a quarter in length. They then scatter and the parent fish leaves them.

Both the eggs and the young fish have numerous enemies. Various sorts of minnows, sunfish, bluegills and young bass are ready to attack them during even a brief absence of the male. Against these the presence of the male fish affords a large measure of protection.

- It appears from the foregoing accounts that the chief points in the process of spawning, as observed by Dr. Reighard, are:

1. The male fish prepares the nest himself, preferably on coarse sand, gravel, or rock, and in a sheltered spot.

2. The female comes to the nest of her own accord or is driven there by the male. 
3. The actual time of spawning is indefinite, but probably averages one or two hours.

4. During spawning both fish are mottled, but the female more conspicuously than the male.

5. After spawning the female leaves the nest of her own accord, or is driven from it by the male.

6. The male then guards the nest until the young fish leave it, and then guards them until they are about an inch in length. During this period he watches them carefully and chases away all intruders.

Although slight variations in the above may occur when bass spawn in large numbers and under natural conditions, yet the facts observed by Dr. Reighard are in the main true, and in accordance with my own observations in natural waters.

Regarding the statement frequently made by anglers that bass have been taken in the summer and early fall ready to spawn, I think there is a false impression.

As soon as a female spawns, the undeveloped ova in the ovi-sacs no doubt begin to grow again, and in a month or two may be quite large. In fact, if one takes the trouble to examine bass in September, it will be seen that all the females will have eggs fairly well developed, especially if the weather be very warm.

In 1905, during the last week of September, I caught female bass at the mouth of the Go Home River, Georgian Bay, which, on account of the unprecedented hot weather, were apparently ready to spawn; hut no doubt with advancing cold weather, these eggs would remain with the fish and not be deposited until the following spring. In a letter received from Dr. Reighard, to whom I wrote concerning this point, he says:

"The ovi-sacs of the bass, as of other fish, are permanent structures which produce the eggs annually. When the eggs of the year have been laid, those to be laid during succeeding years are present in the ovi-sacs. Those to be laid 
the following year are small, but readily visible to the naked eye. They grow gradually until it is time for then to be laid. Whether they grow more rapidly during one part of the year than at other times is, so far as I know, undetermined. The ovi-sacs increase in size with the growth of the eggs of the year, but they are always of good size in a twopound bass, about the bulk of one's little finger when they are smallest. All the eggs that the fish will ever lay are probably present in them when the fish becomes sexually mature; but most of them are then, of course, of microscopic size."

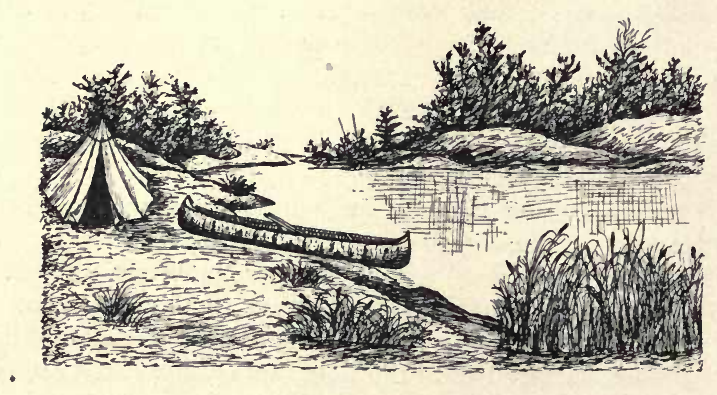




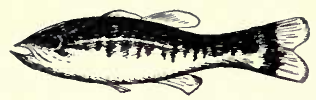

One Month Old

(From Photograph by Dr. Reighard)

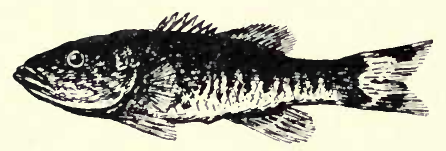

Two Months Old

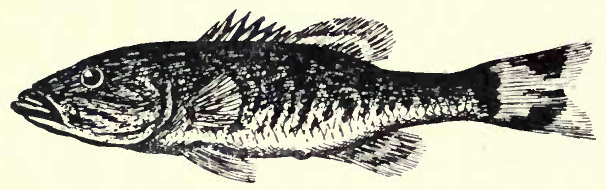

Three Months Old

(From Photograph by B. A. Bensley)

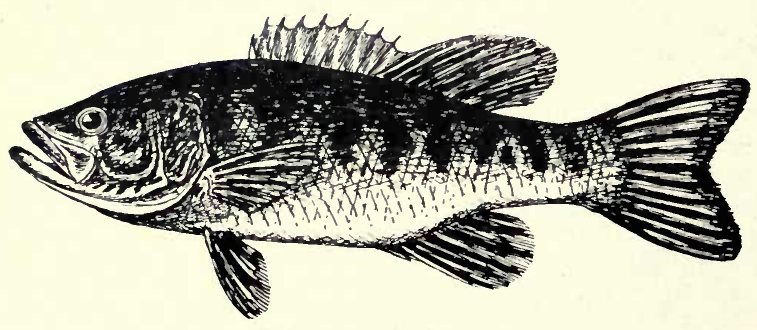

About One Year Old

(From Nature)

SHEWING RELATIVE PROPORTIONS OF YOUNG BASS 


\section{CHAPTER VIII.}

GROWTH,

$\mathrm{T}$

$\mathrm{HE}$ small-mouthed bass develops with extraordinary rapidity, and, although only a fraction of an inch when hatched out in June, it will attain, under favourable circumstances, a length of four inches by the end of the summer season, which rarely lasts longer than three months.

During the second year of its existence it will grow still more rapidly; and by the end of September will probably be eight inches in length and weigh half a pound. In its third season it gradually approaches the lower linit of the angler, ten to twelve inches in length, and weighs from twelve ounces to one pound.

In its fourth season, that is, when it is three years old, it is ready for propagation.

How rapidly it grows after that, and how it develops from year to year, is a matter only for conjecture. Some claim that fish develop indefinitely, although very slowly, after they have reached a certain age; and, that unless killed by starvation, accident or disease, they may live on for ever.

Whether or not there is a limit to their age, as appears to be true in the case of man and animals, involves the whole question of longevity, which hardly admits of discussion here.

How large the small-mouth bass grows is not definitely known; we can only take authentic accounts of large fish that have been caught and weighed, and allow these to stand as records.

A bass, however, of two or three pounds, when in good fighting condition, is a fine fish, and not to be despised, even by the veteran. 
But it is the dream of every ambitious angler to kill, some day or other, a bass weighing at least five pounds; some would probably be satisfied with such a performance, while others, doubtless, place six pounds as the extreme limit of their ambition; and there are still others, a few, who hope to see the day when they may have at the end of their line a fish which will eclipse all previous records.

For the information of all such gentlemen of the rod it may be stated that the largest small-mouthed bass ever taken was one captured by L. D. Boynton, in Glen Falls Lake, New York State, on August 18, 1888, which weighed eight pounds and ten ounces, with a girth of eighteen inches and three-quarters, and a length of two feet, one inch.

Since that time bass have occasionally been caught weighing seven pounds or a little over; but this stands as a record.

No doubt, years ago, larger bass than this have been taken in many of the smaller inclosed lakes of Ontario, but no official record was kept, and it is only recently that any attempt has been made to keep any kind of register of large fish caught in Canada.

The "Star," an evening newspaper of Toronto, commenced in 1901 this work, at the suggestion of Mr. J. T. Clark, and the following list shows that we may yet hope to improve on the present record of 8 lbs., 10 ozs.:

1901-John King, Havelock; fish caught in Balsam Lake, 6 lbs., 4 ozs.

1902-A. S. Laing, St. Catharines, fish caught in Rice Lake, 5 lbs., 13 ozs.

1903-John J. Irwin, Smith Township, fish caught in Clear Lake, $7 \mathrm{lbs}$.

1904-J. E. Smith, Verona, fish caught near Verona, 6 lbs., 14 ozs.

1905-H. C. Barker, Toronto, fish caught at Trent Bridge, 6 lbs., 11 ozs. 


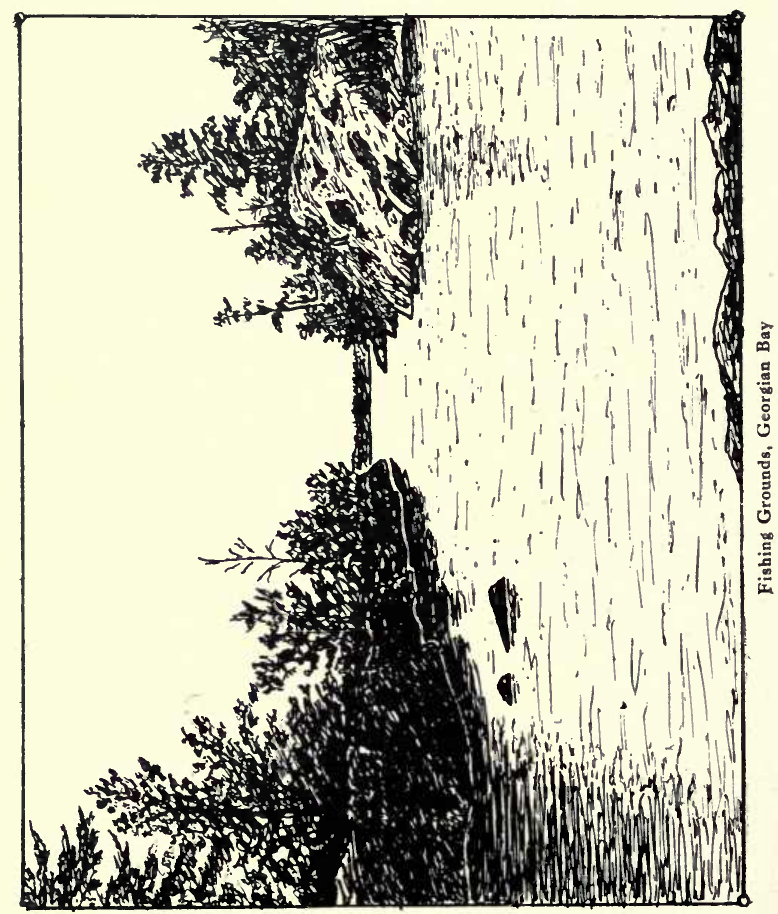


1906-Wm. Robson, Harwood, Rice Lake, fish caught in Rice Lake, 7 lbs., 3 ozs.

1907-J. C. Bloomer, Toronto, fish caught in Lake Koshee, 6 lbs., 8 ozs.

1909-Johnnie Anderson, Malta, fish caught in Lake Koshee, 6 lbs., 6 ozs.

It is difficult to make any suggestions, either to amatetirs or to veterans, who may be ambitious enough to try to eclipse these records; for the beginner may accidentally land a big fish, whilst the veteran may fish all his life and get none but those of mediocre size and weight. Two general rules, however, may be laid down for the guidance of anglers: firstly, to fish in unfrequented lakes of small dimensions, where food is plentiful and therefore the fish are likely to reach a great size; and, secondly, to fish in all possible places, at all possible times, making angling a chief pastime, so that, by the doctrine of probabilities, one may, during the course of a long life, chance to get a fish of record size; always remembering that there are bigger fish in the sea than were ever taken out by the hand of man.

My own experience has been that of the average individual: the only large fish I ever caught was one taken in August, 1878, in Four-mile Lake, near Coboconk, weighing 6 lbs., 4 ozs.; another, which I caught in July, 1888, at Lac St. Joseph, north of the City of Quebec, (one of the few lakes in the Province of Quebec which used to contain small-mouthed bass), weighed 5 lbs., 3 ozs.

But I have a dim recollection that, as a small boy, I was accustomed to go angling every summer, during June and July, to the aforementioned Four-mile Lake, and that once, when fishing from the top of a fallen pine tree which projected over the edge of the lake, I was pulled into the water by a monstrous bass, which always haunted this Pine Tree Top and had become famous, all the country round, as a destroyer of lines, rods and baits; and that, some days after- 
wards, a gentleman named Stalker, from Toronto, caught this fish, which seemed to me about three feet in length; and although what appears large in childhood dwindles down considerably when viewed after a lapse of years, yet I have always had a desire to revisit that lake and catch another such fish. I feel confident that it would weigh at least ten pounds.

In estimating the size of a fish it is usual to measure its length, girth and weight.

The length is determined by laying the fish flat on a board and measuring the distance from the end of the snout to the line joining the two projections of the fork of the tail.

If the fish be very long, it is necessary to raise the tail slightly, by placing under it a small block of wood, so as to bring it into the plare of symmetry of the body.

The girth is the greatest distance around the body of the fish, measured with the back fin closed.

The weight is best obtained by some reliable form of platform scales or steelyard; the ordinary spring-balances being liable to considerable error, especially if they have been in constant use.

The length and girth are usually estimated in inches, and the weight in pounds or ounces (avoirdupois).

To give some idea of the relations existing between length, girth, and weight, I insert here in tabular form the dimensions of various fish. They represent average "shoals," such as swim about from place to place throughout the summer months: 


\begin{tabular}{|c|c|l|}
\hline L. & G. & W. \\
\cline { 1 - 2 } 16.50 & 11.5 & 39 \\
\cline { 2 - 3 } 13.50 & 9.75 & 21 \\
13.25 & 9.00 & 20 \\
13.00 & 8.00 & 16 \\
12.75 & 8.00 & 14 \\
12.00 & 8.75 & 16 \\
12.00 & 7.50 & 11.5 \\
11.75 & 8.00 & 13.5 \\
11.50 & 7.50 & 11 \\
& & \\
\hline
\end{tabular}

August, 1905

\begin{tabular}{|c|r|l|}
\hline L. & \multicolumn{1}{|c|}{ G. } & W. \\
\cline { 1 - 2 } 15.00 & 10.75 & 31 \\
\cline { 2 - 3 } 15.00 & 10.00 & 27 \\
14.50 & 10.00 & 26 \\
14.75 & 9.75 & 24 \\
13.50 & 9.00 & 20 \\
13.50 & 8.50 & 20 \\
13.00 & 9.00 & 20 \\
14.00 & 8.50 & 18 \\
13.50 & 8.75 & 17.75 \\
& & \\
& & \\
\hline
\end{tabular}

July, 1904

\begin{tabular}{|c|r|c|}
\hline L. & \multicolumn{1}{|c|}{ G. } & W. \\
\cline { 1 - 2 } 15.25 & 10.00 & 28 \\
13.50 & 8.50 & 18 \\
13.25 & 7.75 & 15 \\
13.00 & 8.25 & 16 \\
13.00 & 8.00 & 14 \\
12.50 & 7.75 & 14 \\
12.25 & 7.25 & 13 \\
12.25 & 7.00 & 13 \\
12.00 & 7.50 & 13 \\
11.75 & 7.25 & 11 \\
& & \\
\hline
\end{tabular}

August, 1900

\begin{tabular}{|c|l|l|}
\hline L. & \multicolumn{1}{|c|}{ G. } & \multicolumn{1}{|l|}{ W. } \\
\cline { 1 - 3 } 14.00 & 8.50 & 18 \\
13.50 & 8.75 & 17.75 \\
12.50 & 8.00 & 15 \\
12.50 & 8.50 & 16 \\
12.25 & 8.50 & 15 \\
11.75 & 7.00 & 10 \\
11.50 & 8.00 & 13 \\
11.50 & 8.00 & 13 \\
11.25 & 6.75 & 10 \\
11.25 & 7.50 & 11 \\
11.00 & 7.00 & 10 \\
& & \\
\hline
\end{tabular}

July, 1902 
A general relation connecting the three quantities $L$, $\mathrm{G}, \mathrm{W}$, may be constructed empirically by assuming that

$$
\mathrm{W}=\mathrm{KG}^{2} \mathrm{~L}
$$

which is in accordance with the ordinary laws of symmetry.

As a matter of curiosity I computed the value of $\mathrm{K}$ from a large number of observations extending over many years, and found it to be given approximately by the fraction $\frac{1}{55}$.

Consequently one may, with small error, obtain the weight of any small-mouthed bass by measuring the length and girth, and then using the above law.

Multiply the length in inches by the square of the girth in inches and divide the result by 55. This will give the weight in ounces avoirdupois.

For this one needs only a small tape line or measuring rod.

This formula holds fairly well for bass which weigh three pounds or less: the probable error being not more than one ounce; but whenever fish weigh much over three pounds the error becomes very great.

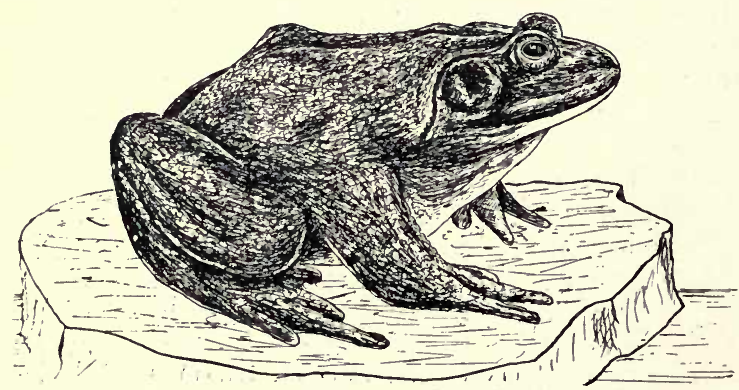

Bull Frog 


\section{CHAPTER IX.}

\section{TRANSPLANTING.}

D

URING the past ten years great advances have been made in the endeavour to stock private and public ponds, lakes, and streams with the small-mouthed bass, owing to the growing demand of sportsmen and of the general public for resorts where one may spend a few days in angling for this game fish.

Of the methods adopted, artificial fertilization and hatching, such as is practised with trout, seems to have been unsuccessful, if not quite impracticable. Various attempts have been made to hatch bass artificially, but the difficulty of obtaining proper conditions, and especially satisfactory temperatures, has been so great that the scheme has been abandoned.

At present, either the fully developed fish, male and female, are actually transplanted from one place to another in suitable tanks, and allowed to spawn naturally; or else, ponds are constructed where the fish spawn under semi-natural conditions; and the small fry are then caught, when from one inch to three inches in length, and shipped to their destination. The former plan, that of transferring adult fish, seems open to the objection that they may die if placed in waters quite different from those in which they have been reared, owing to the difficulty of sudden acclimatization. The second plan, that of raising small fry from adult fish placed as nearly as possible in natural conditions, and then transplanting these, seems more reasonable and has proved more feasible and satisfactory.

The most scientific account of transplanting bass is given in the Report of the Michigan Fish Commission by 
Dr. Reighard, referred to previously, and I quote from that report the following facts which seem to be most interesting to the average angler and fisherman:

\section{Artificial Fertilization of Black Bass Eggs.}

In nearly all fish propagated by fish culturists it is the custom to press or "strip" the eggs from the female, to fertilize them with milt stripped from the male, and to hatch them in a suitable hatching apparatus. The procedure is known as "artificial propagation," of which "artificial fertilization" is a necessary part. This method of dealing with the bass naturally early suggested itself to fish culturists.

Tisdale (1869) was the first to attempt the artificial fertilization of black bass eggs. He says: "The act of emitting their spawn I have never seen; and repeated efforts to express it from these fish in May, when supposed to be ripe, for the purpose of artificial impregnation, proved abortive. The ova of this fish are small, about one-fourth the size of salmon or trout spawn, very compactly laid in a film covered sac and apparently difficult to escape through any artificial process. Further experiments beyond doubt will effect this."

For many years fish culturists do not seem to have repeated Tisdale's attempt at artificial fertilization. It was generally held that the parent bass gave such good care to its eggs and offspring that nothing more than the introduction of adult bass was necessary to stock any water. Thus Seth Green (1877), Henshall (1880), Goode (1884), and Holt (1886), held to the view that artificial cultivation of the black bass in any form was either impossible or unnecessary.

Some ten years ago, owing to the increased interest taken by anglers in the black bass, and owing to the depletion of some bass waters, urgent requests for the artificial cul- 



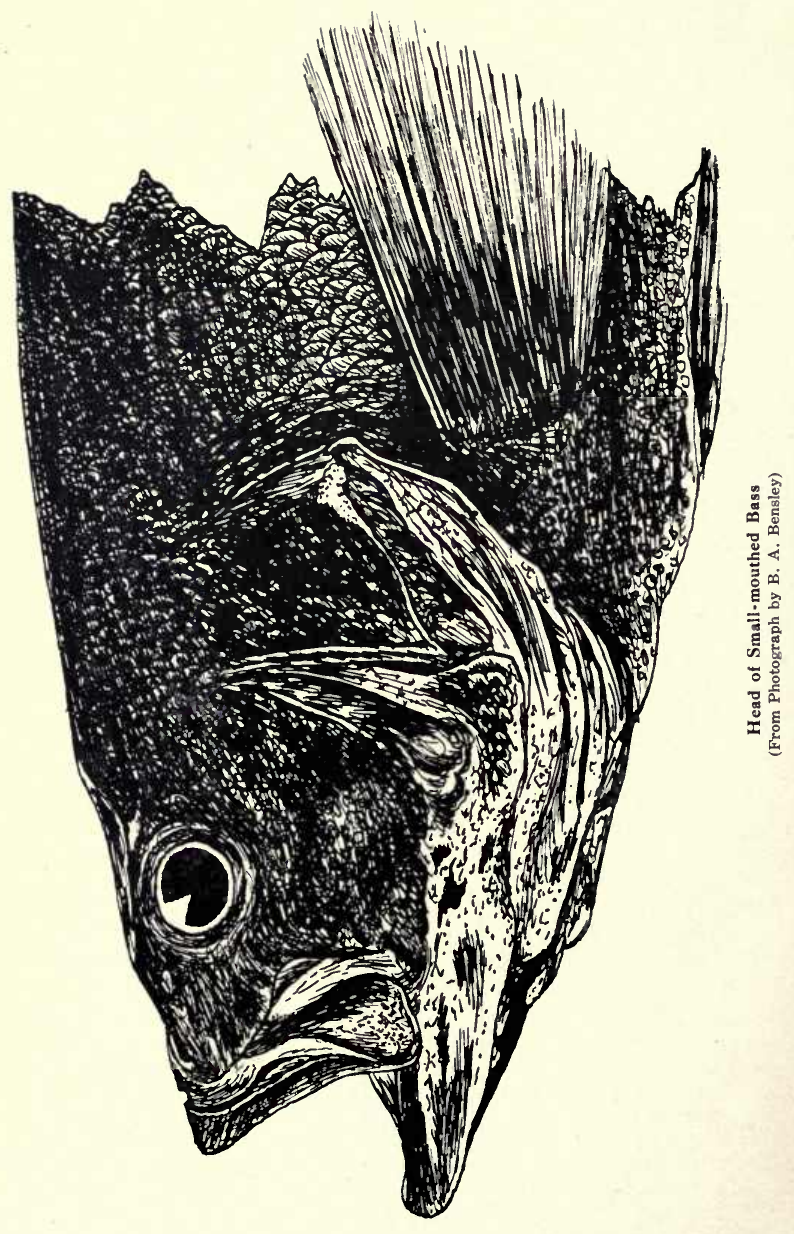


ture of this fish came to the United States Fish Commission as well as to the State Commissions. We then find renewed attempts at artificial fertilization. Thus in 1896 Page (1898), at the United States station at Neosho, Missouri, took wild black bass in April, confined them in a pool until the end of the season and attempted artificial spawning, but without success. Failure was attributed to the low temperature of the pond selected. The species used is not stated.

In the same year Stranahan (1898) took males and females of the small-mouthed black bass from their beds, apparently in the act of spawning. "But in only one instance were fry hatched from eggs collected in this way. The eggs were forced from the female with great difficulty, and in no instance could milt be obtained from the male; hence it became necessary to open the fish and remove the spermaries, which were then cut up and mixed with the eggs, a little corn starch being added to prevent adhesion." Eighty-five per cent of these eggs were impregnated. They hatched in four days.

Again, in the same year, Lydell (Bower, 1896; Lydell, 1902) attempted artificial fertilization in small-mouthed bass seined from their beds while spawning. He succeeded in this way in stripping two females, but in order to secure milt found it necessary to open the males. About 60 per cent. of these eggs were hatched. Bower (1896) concludes that artificial impregnation is impossible. He says: "A preliminary coaxing or caressing by the male seems imperative, not only to bring the female to the point of spawning, but also to develop the milt. These preliminary proceedings are sometimes carried on for several hours and again only for a few moments; if the fish are interrupted or handled at this time, or prior to the orgasmic stage, neither the eggs nor milt will flow, so that artificial impregnation may be accomplished only during the few moments of actual 
spawning or after the natural spawning has begun. Under the strictest surveillance the opportunity is too seldom presented or known for practical operations in this direction. In any event, however, we would lose instead of gain by the artificial handling of bass eggs, owing to the relatively high percentage of natural results in protected ponds and the relatively low percentage of results by artificial treatment of adhesive eggs."

As the result of these several attempts artificial fertilization was rightly abandoned as impracticable.

Pond Culture.

This is the method now universally employed for hatching bass and consists in the construction of a pond which shall as nearly as possible resemble a natural lake, with plenty of vegetation and with water about six feet deep, and a surrounding edge of shallow water from ten to twenty feet in width. This strip or terrace, as it is termed, carries the artificial nests used by the bass when spawning.

These nests are merely cubical boxes, open at the top and at one side, having the bottom filled with coarse gravel, which helps to keep the box in an upright position, and enables the bass to spawn. The open side faces the deep water, so that in reality the bass, when spawning, are shielded on three sides.

The pond should have a bottom of good soil, intermingled with sand, so as to support a rich growth of water plants.

Three hundred fish may be kept for breeding purposes in a pond which has an acre of surface. They are fed on live minnows, preferably; and in the fall of the year, when minnows become scarce, they may be fed with liver, cut into small strips; but the live minnow forms the best diet. In fact, it is probable that the continual feeding on liver during the fall season renders the fish incapable of supporting the hibernation of the winter and the subsequent spawning of the following spring. 



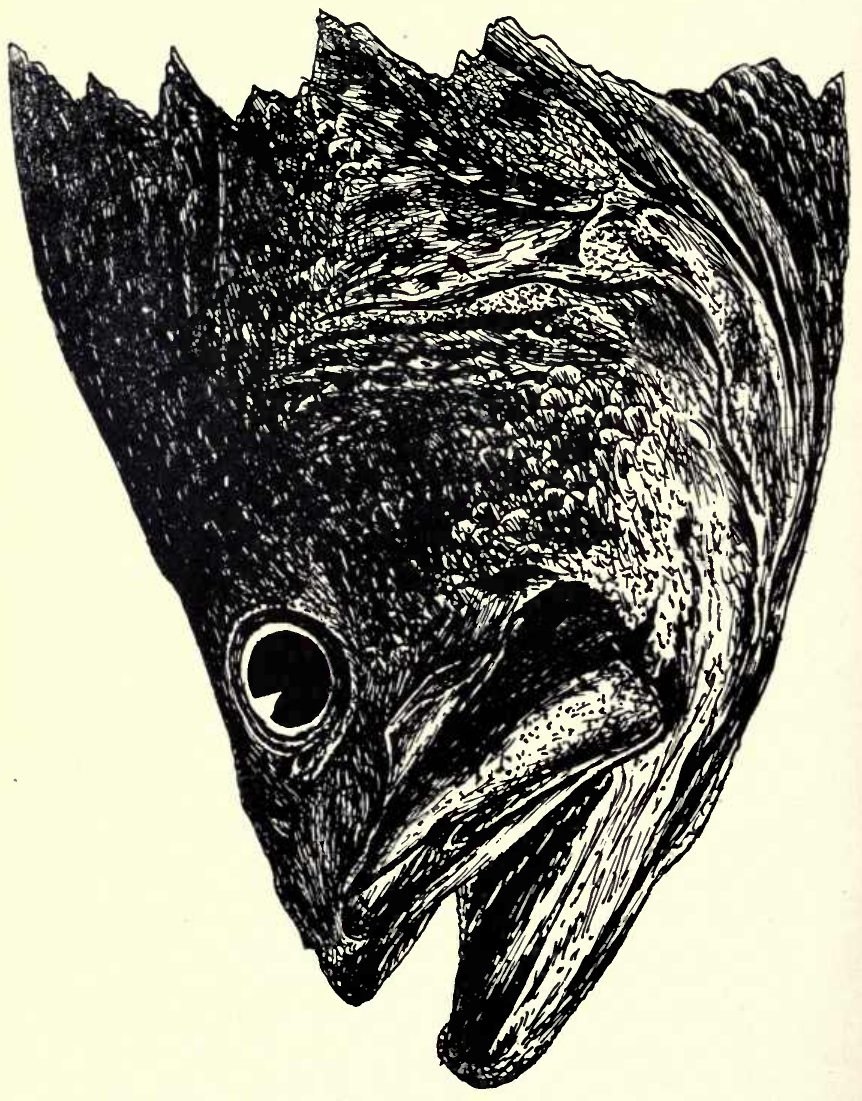

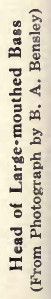


Special precautions are taken for the cleansing of the ponds from time to time and the renewal of the water, as well as for collecting the fry for shipment after they are hatched.

(See Bulletin of Michigan Fish Commission, No. 7.)

In a summary deduced from observation and experiment by Mr. Dwight Lydell the main points are as follows:

1. Three methods of bass propagation have been tried,artificial fertilization and hatching, pond culture, and transference.

2. Artificial fertilization has been found impracticable and has been abandoned.

3. Pond culture is the method now universally employed and has resulted in the following practices and devices:

a. Ponds are now commonly built on the model of the natural pond.

b. It is the practice to have the ponds well grown with vegetation.

c. In ponds intended for small-mouthed bass it has been learned that the temperature and turbidity of the water are important and must be controlled.

d. Brood fish are sorted just before the breeding season, so that the males in any pond shall not be in excess of the females.

e. Brood fish are fed as far as possible on minnows.

f. Artificial nests have been gradually evolved. The earliest nests were merely gravel piles. The latest forms are the shielded and screened nests of Lydell, designed to afford shelter for the parent fish and a suitable material upon which to lay the eggs; gravel for the small-mouthed bass and fibre for the large-mouthed.

4. The difficulty which still remains to be overcome in pond culture is the death of eggs before or soon after hatching.

5. This death is to be attributed to lack of vigour of the parent stock, and a remedy is to be sought in the following directions: 
a: By maintaining a more vigorous breeding stock, either by annually replacing the stock with fresh breeders from the natural waters, or by rearing the breeders from the egg in the artificial ponds or by selection.

b. By keeping the brood fish under more natural conditions, in larger and deeper ponds, or, in the case of the small-mouthed bass, where practicable, in running water.

6. The age at which young bass should be planted is dependent in some degree on the kinds and relative abundance of the fish already in the waters to be planted, but present experience does not warrant the expensive practice of rearing large fingerlings or yearlings.

7. Transference of adult fish should be tried experimentally and may be found to be feasible for certain regions or under certain circumstances.

Two clauses of the foregoing may be specially noticed. The first relates to the lack of vigour of the parent stock, which no doubt causes the death of a large percentage of eggs; and the second to the age at which bass should be transferred, whether in the form of small fry, fingerlings, or adult fish.

These are the crucial problems in the hatching of bass, and the nearer one approaches natural conditions the better the results.

My own experience on these questions leads me to suggest that for the small-mouthed bass, which is peculiarly susceptible to changes of temperature, and probably also to slight changes in the chemical constituents of the water, no plan is better than the one I tried some years ago with success in Georgian Bay. I selected a pond with a narrow inlet into the bay not more than a few feet in width, and, after carefully stripping it of pike, catfish, dogfish, sunfish, etc., I had a screen of brass wire, one-quarter inch mesh, placed across the outlet. 
I then caught thirty-three small-mouthed bass, some with hook and line, a few with a net, varying in length from eight to eighteen inches and in weight from six ounces to three pounds.

There were probably an equal number of males and females. These I placed in the pond about the last week of September.

The following spring there were at least a dozen nests at different points on the shore, and during the summer I saw hundreds of small bass, varying in length from one to three inches, swimming about in shoals. The screen was finally removed and the bass gradually escaped into the lake.

This experiment convinced me that the proper method of stocking any pond or lake is to hatch the bass in water of a similar character and transfer them when they are two to four inches in length; but I doubt whether any small pond will support small-mouthed bass for a great period of time, even with every artificial contrivance known.

What these fish seem to require more than any other species is clean, cool, running water. They may live without it for a length of time; but it is as essertial to them as fresh air is to human beings, and probably acts on them in a similar way.

Transferring adult fish from ore lake, where the water is perhaps dark and soft, to another lake where it is clear and hard, or vice versa, certairly does not seem reasonable. The small-mouthed bass is doubtless affected by slight variations in the chemical and mecharical structure of the water as it is by slight variations of temperature, and it is for this reason, I think, that large numbers of this fish which have been shipped in tanks, during the spawning season, from one lake to another, have never developed as they should and have gradually disappeared in course of time.

To transfer fry or small kass, four to eight inches in length, from one water to another, is certainly more likely to suc- 
ceed, owing to the greater probability of acclimatization of the younger fish.

It would seem that two general rules should be followed in the problem of transference of bass:

1. The chief essential to the development and growth of the fish being clean, cool, running water, no pond or lake should be stocked with them unless its waters are being constantly renewed.

2. When these fish are placed in any body of water, they should be taken from waters as nearly as possible similar in every respect to their destined home.

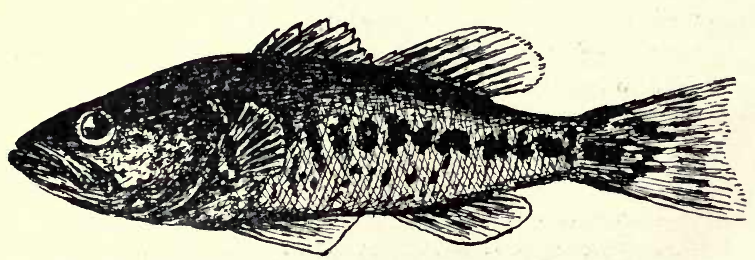

Large-mouthed Bass, One Year Old

(From Photograph by B. A. Bensley) 


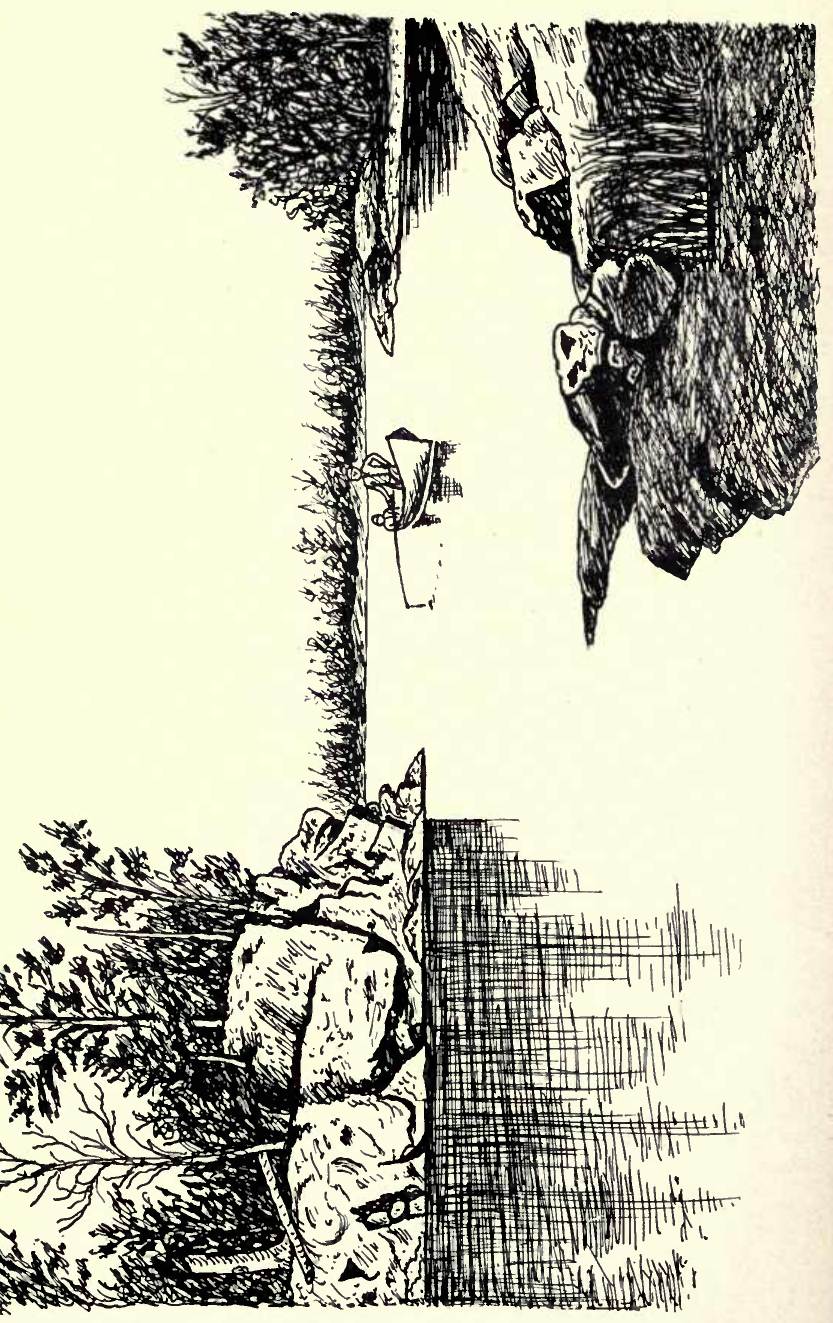

党

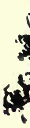




\section{CHAPTER $\mathrm{X}$. \\ Bass Fishing in Georgian Bay.}

EORGIAN BAY lies between the parallels of latitude

I 44 and 46 and is about 125 miles in length, with an average width of 40 miles. As previously stated, its eastern shore, which is rocky and totally unfit for agricultural purposes, is broken by innumerable bays and inlets, some of which penetrate the land for miles.

Many of these inlets form the mouths of streams and rivers, which carry down vast quantities of organic matter and food for fish. In addition, the shore is strewn with islands, rocks, and sunken reefs, which protect it during periods of high winds, so that even in rough weather one may pass, by boat or canoe, along the coast amongst these islands, except at one or two points, and travel in safety all the way from Beausoleil Island to the mouth of the French River.

Some idea of the total number of islands may be gathered from the recent survey made by the Indian Department at Ottawa, which places the actual number of islands and islets lying south of Moose Point alone at 2,180.

The prevailing wind is west, and in consequence of this the waters of Georgian Bay are piled up against the eastern shore on an average two or three times a week; this rising of the water is then followed by a lowering, sometimes as much as twelve inches, seldom less than two inches, and oscillations of the Bay are thus set up, as in all large bodies of water; so that there are always strong currents running in and out of the inlets and in the channels between the islands and the mainland and between the islands themselves, which keep the water aërated and clean.

There are also innumerable small ponds or lakes connected 
only with the open water by narrow channels, sometimes only a few feet in width; and these, owing to the constant rise and fall in level, are kept perfectly clean and well supplied with a change of water.

If one attempted to establish artificially a perfect resort for small-mouthed bass on a large scale, no better model could be taken than any of the natural hatching ponds on

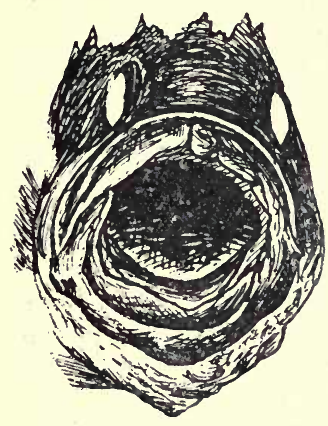

Head of Small-mouthed Bass (From Photograph by B. A. Bensley) the eastern shore of Georgian Bay.

This being the case, it is the duty of the Ontario Government, or of the Dominion Government, or of both, to protect this ideal fishing ground, not only as a source of revenue to the surrounding community, but as a breathing spot, where one may obtain fresh air during the hot summer months, combined with a moderate amount of recreation in the form of angling.

No country should allow such a valuable asset to become unprofitable; and if, in the past, owing to doubtful jurisdiction or to politics, or to divided interests, this district has been allowed to remain undeveloped and a prey both to fishermen and to anglers, the fault lies, not with the general angling public and sportsmen, but with those authorities who frame our fishing laws and also with those who attempt to carry them out.

At present there is established an imaginary line or limit within which no net is supposed to be set, running almost north and south, and lying probably two or three miles from shore, so as to inclose all the islands.

But the inspection necessary to prevent fishermen from 


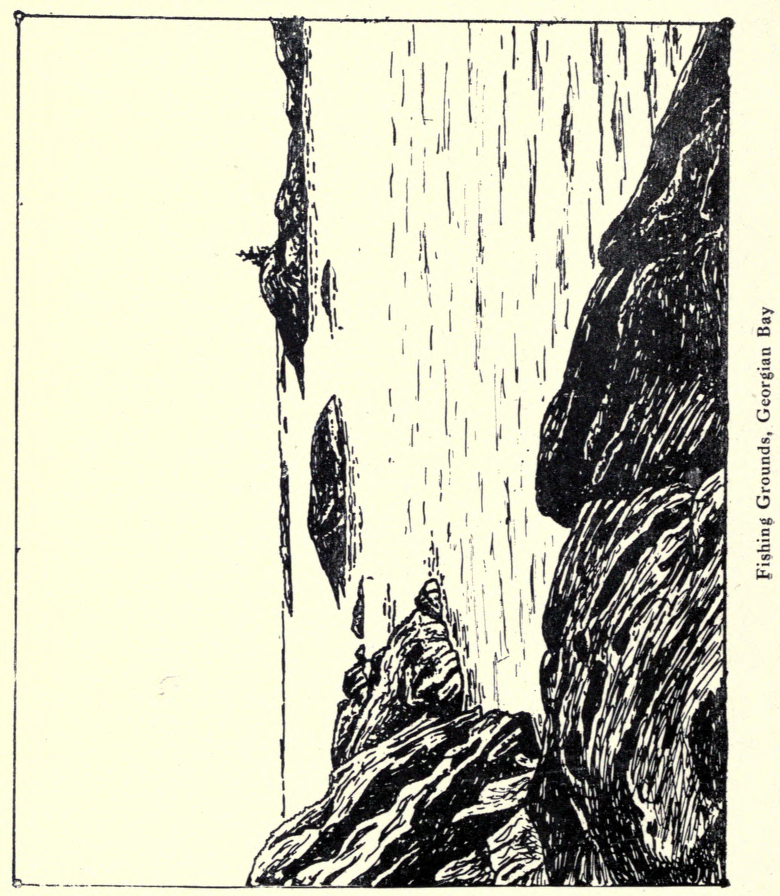


setting nets in this reserved area is not of a nature to accomplish much reform. The Ontario Government, under whose charge the actual inspection of this reserve now lies, should appoint at least three men who are thoroughly familiar with the shore, by preference fishermen themselves, and provide each of them with a fast gasoline launch and an assistant, and pay them salaries sufficient to keep them in comfort throughout the year, and above suspicion.

Then assign to each man a third of the shore line, and take care that the work of inspection begins as soon as the ice breaks up; for it is just at that time when all the serious damage is done by fishermen.

During the months of April, May and June these inspectors should be specially on guard. In the summer months of July and August, when tourists

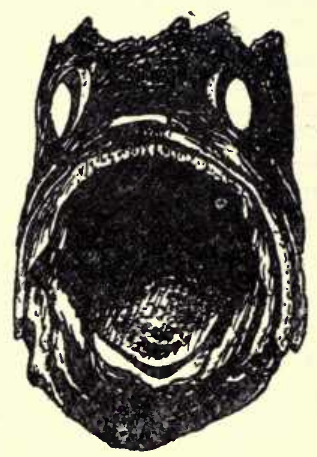

Head of Large-mouthed Bass (From Photograph by B. A. Bensley) are in full force and the fishermen are lying on their oars, let them patrol the shore for anglers who are in the habit of making record "catches" of bass. And then let them continue their work until the ice forms, and even during the winter. For although there is no danger of anyone taking a small-mouthed bass in winter, there are other fish which are not so wise as to hibernate, and these should be protected from themselves.

If such a policy were carried out, combined with some system of producing a proper revenue, and the fish markets closely watched, there would be such an improvement in Georgian Bay as to astonish even a Commissioner of Fisheries.

Regarding the hatching of bass, there are natural hatch- 
ing ponds, all ready for use, in hundreds along the shore. Any of the fishermen who live throughout the year on Georgian Bay would be glad to earn a few dollars in stocking these ponds and inlets with bass, which could then be allowed to breed naturally (and their young to escape into the open bay). By this method, re-stocking could be carried on indefinitely and at sniall expense.

But the whole problem is not easy of solution. Where there are two parties: on the one hand, fishermen, who have grown up from youth with an oar in one hand and a net in the other, whose whole life has been one of independence of the laws which govern mere landsmen, who regard themselves as having in some way a divine right to extract fish from the water by any means within their power, and finally, to whom a fish diet is as necessary as a meat diet to the ordinary dweller in cities; and on the other hand, politicians, whose daily life is consumed in an attempt to catch votes by fair means or foul, who trim their sails to every passing breeze, and who, leading a life of continual excitement and worry, choose any port in a storm, there is not much consideration likely to be given, except in the form of occasional bait, to the poor, miserable angler. And, until someone in power, with brains enough to realize its value and independence enough to carry out a plan of improvement, makes a study of conditions and forces the proper authorities to act, there will be no redemption of Georgian Bay. 

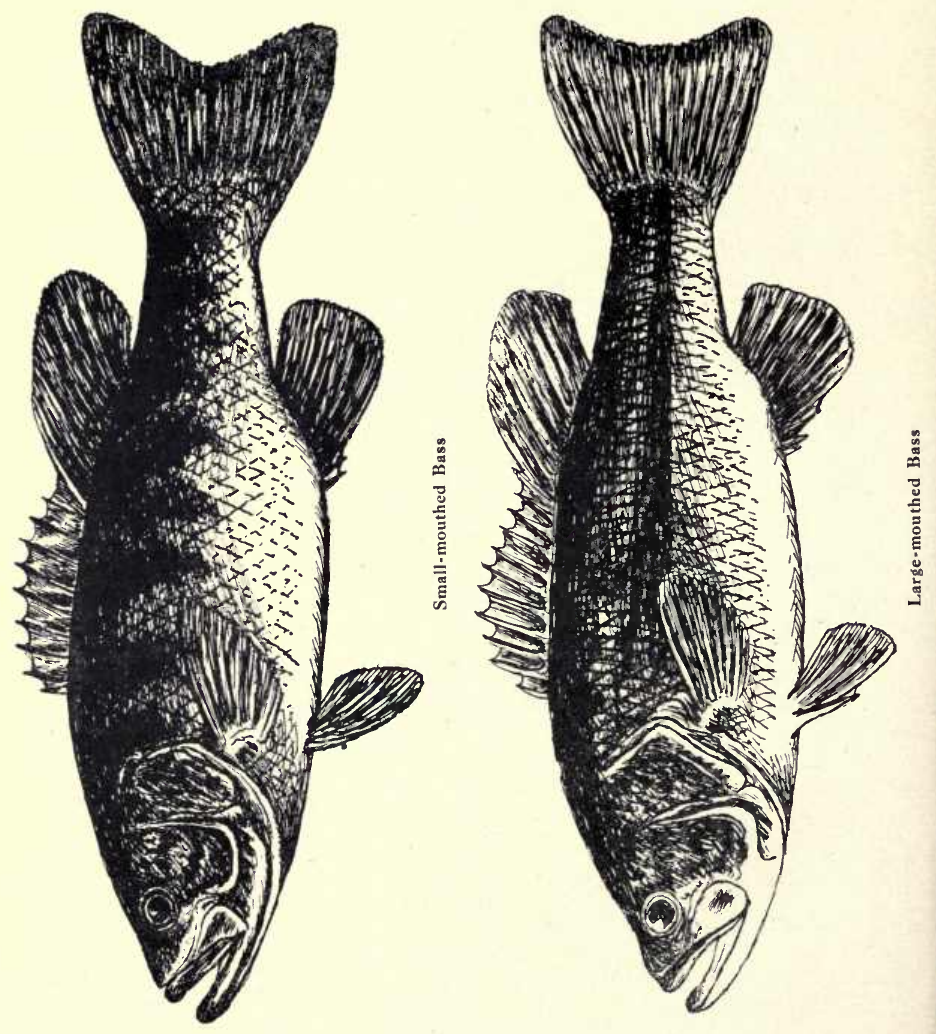


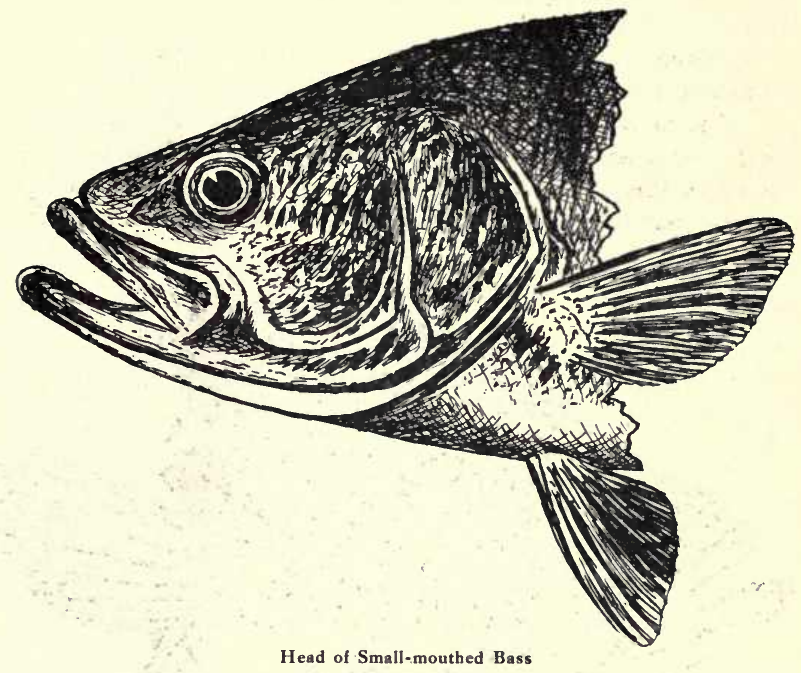

CHAPTER XI.

The Smali,-Mouthed and the Large-Mouthed Bass.

LTHOUGH, to the inexperienced eye, the two species
of bass resenble one another closely, they are in reality not as much alike as the pike and maskinonge. The main point of difference lies in the mouth, which enables one to distinguish them at a glance, and which has therefore given them their respective names.

In the small-mouthed bass the angle of the mouth lies well in front of a vertical line drawn through the centre of the eye, while in the large-mouthed species the mouth extends far beyond such a line, and gives the fish, when the mouth is wide open, a most savage appearance. 
Moreover, the general outlines of the two fish are seen, on close inspection, to be quite dissimilar.

The large-mouthed bass is broader and has a fiercer looking eye; and its colouring is much lighter. This is true, even in the case of the young fry only a few months old.

Its habits are the reverse of its small-mouthed brother.

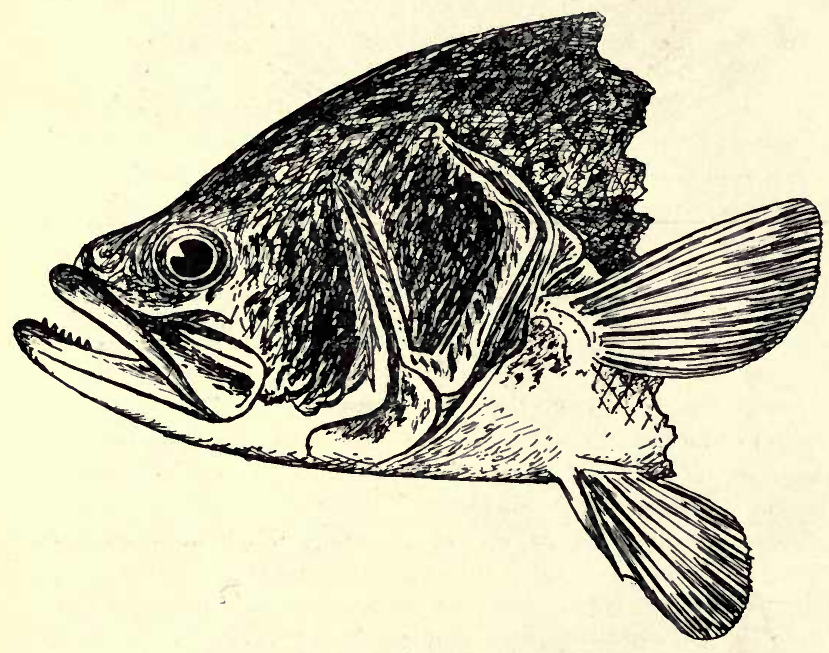

Head of Large-mouthed Bass

It haunts the edges of ponds and lakes, lying amongst weedbeds and in the mud, and seems to thrive in stagnant water, although it probably would prefer clean water if food were plentiful.

But it is a most voracious fish, and no doubt food is its first consideration.

In consequence, it will always be found close to shore, 
where it gobbles down anything which comes in its way, from sunfish to snakes or young nuuskrats.

I have frequently caught fish weighing not more than two or three pounds with rock bass in their stomachs the size of a man's outstretched hand.

In rivers, where currents run strongly, it is a game fish, and will put up a fight like the small-mouthed bass; and, as it grows to a much larger size, there are many anglers who prefer it to its smaller brother.

It will also take any kind of artificial or natural fly, especially towards evening; and one may wade along the edge of a pond or walk along a river bank, and get as good sport, where they are plentiful, as with the speckled trout.

They grow rapidly, even under difficulties, and to a great size, it being no uncommon thing to catch one weighing five or six pounds; and occasionally they have been taken weighing ten to twelve pounds. Their flesh, naturally, from their mode of living, is not very clean or sweet, and especially in the hot summer months, is not much better than that of the pike. If, however, one takes them from clean water, their flesh is just as delicate and as firm as that of the pickerel or perch.

They are very savage when young, much more so than any fish I know, and will eat one another when nothing else is in sight. Only a short time ago I saw a little green bass, about two inches in length, chase a silver shiner close to the edge of a pond, and, as the latter jumped to escape, he seized it in his mouth, while the impetus of his rush carried him out on the shore; and I picked him up, with the shiner well down his throat and its tail sticking out of his mouth. The shiner was as long as himself, and when I threw them both back together into the water, he was nothing daunted, but seized his prey again, half swallowed him and, like a flash, disappeared from view. 


\section{CHAPTER XII.}

How to Cook the Bass.

$\mathrm{T}$ HERE are no fish which spoil so rapidly in hot weather as the small-mouthed bass, and therefore, when caught, they should be at once killed and put in a cool place, protected from the sun, and, as soon as possible, scaled and cleaned.

Scaling.

The scales are removed by a useful little instrument known as a scalar, made of a piece of half-inch straight pine, in the form of an ordinary hair brush, and studded with inch nails.

Small holes should be bored in the scalar with an awl,

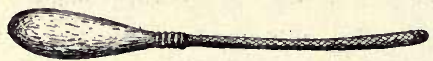

Billy for Killing Bass

so that the nails when driven in will not split the wood; and equal portions of the head and point of the nail are allowed to project on each side. Iron scalars are sold in the stores. With the aid of such an instrument any fish may be scaled in a few seconds, provided one performs the operation before the fish become dry and the scales harden.

\section{Cleaning.}

After scaling, the fish is cut open along the belly and the gills and entrails removed. It is then washed out with clean water, so that no blood is left behind; but it should not be allowed to lie soaking in water, which would spoil its flavour.

It is now ready for use. 
Storing and Shipping.

If a refrigerator or an ice-house be available, bass may be kept indefinitely by placing them in a box, with the bottom resting on a bare block of ice, and then strewing over on top of the fish pieces of broken ice, which may be renewed when melted. Care must be taken, however, to provide small outlets in the bottom of the box, through which the melted ice may escape.

When bass are to be shipped any distance a small quantity of coarse salt is sprinkled along the back bone, and they are

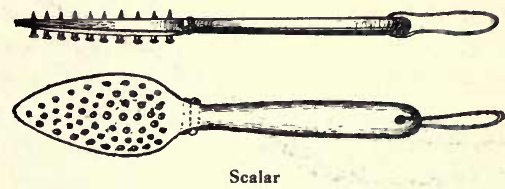

packed in a box with cedar or hemlock branches. Grass or sawdust should not be used for this purpose. They will then remain quite fresh for twenty-four hours. If packed with a layer of ice on the bottom of the box, then a layer of branches, then the bass, then another layer of branches, and finally a layer of broken ice on top, with a small hole in the bottom of the box for drainage, they will be fit for use after a voyage of two or three days.

When there are no conveniences for packing, or one is pushed for time, bass may be scaled, cleaned, dried, and wrapped tightly in a piece of cheese cloth and then in a piece of thick brown paper. I have carried them, so packed, in a closed satchel, on an extremely hot day in July, with a maximum temperature of ninety degrees Fahrenheit, and found them fresh at the end of a twelve hours' journey. 
Cooking.

Like the rock bass and perch, the bass is essentially a pan fish, and when taken from the water and cleaned immediately, cut in small pieces and fried in a pan with bacon, it is unsurpassed in flavour by any fresh water fish, even the speckled trout.

It seldom has any of the rich fat which causes other fish, like whitefish and trout, to pall on the taste, and on this account it is an especially good diet for invalids.

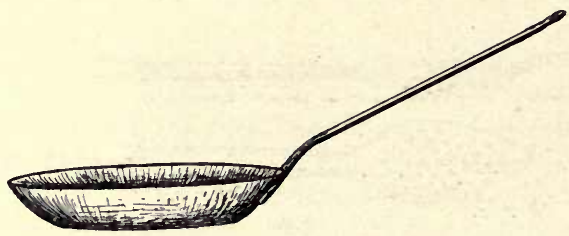

Proper Shaped Pan for Frying Fish

Various methods may be employed in its preparation for the table, of which the following may be mentioned:

In camp, the Indian custom may be employed, which is simple, primitive, and requires no utensils. The fish, when taken, has a green stick of birch run through it, and it is then propped up against the camp fire and turned occasionally so that it may be cooked on all sides. In ten or fifteen minutes it will be ready to eat, when the outer skin and scales are removed with a jack-knife. The stick is left in the fish and serves as a handle; and the flesh may then be sprinkled with a little salt and eaten $a$ la nature.

Or, it may be baked on a hot stone either in its natural state, or after it has been scaled and cleaned.

For civilized society, place a frying pan on a hot fire of coals or wooden embers, and fill it to the depth of half-an- 
inch with bacon fat, dripping, butter, or, preferably, pure olive oil; lard, unless pure and freshly rendered, is most objectionable and is to be avoided. Slices of fish are then dipped in a bowl containing two or three eggs thoroughly beaten up, and are covered completely with bakers' flour, or finely crushed soda biscuits, or, best of all, with finely powdered oatmeal, cornmeal, or peameal. When the oil or fat has reached a temperature of about $300^{\circ} \mathrm{F}$., the pieces of fish are placed carefully in the pan and turned only once. The operation of frying requires great care and attention and can only be learned by experience.

When removed from the pan the pieces of fish should have a delicate brown shade, uniform all over, just about the colour of properly made toast.

Served with slices of bacon, small, tender, freshly plucked cucumbers, and fried potato chips, it is a dish which appeals either to the delicate palate of the invalid, or to the coarse, promiscuous appetite of the gourmand and glutton.

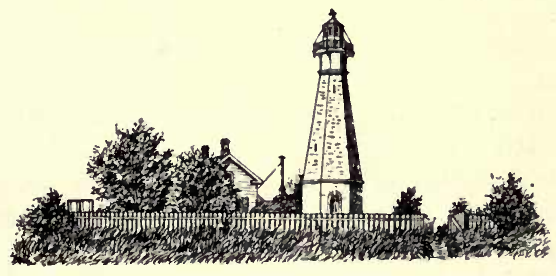




\section{APPENDIX.}

\section{Hints TO ANGLERS.}

1. For any kind of fishing, the choice of a proper hook is most important. The barb should have a needle-like point and should lie in the same plane with the shaft; and the size of the hook must be suited to the nature of the angling and the bait used.

The fine point of the hook soon becomes dulled by constant wear, and, although it may be filed down again to a point, it is never the same, and should properly be discarded, especially when one fishes along a stony bottom.

More fish are lost by using blunt hooks than from any other cause.

Double gut hooks are to be preferred, the gut being, as nearly as possible, the colour of the water. Gimp hooks are uncertain in their action, as the gimp is liable to tear asunder at any moment. This is more particularly the case when they are not carefully dried out after being used.

One good hook with double gut should catch one dozen (?) bass; it should then be inspected, and, if the point be dull, thrown away.

Hooks which are a year or more old, even if they never have been used in the water, will not last as long as those freshly made, the gut becoming brittle, and the shellac about the shaft disintegrated.

The best hooks are those prepared by the angler himself, wound with silk and black shellac, from the best quality of gut.

For some reason, the black hook is more durable than that of a bronzed or silvery colour.

2. Do not angle with dead or half-dead bait, because 



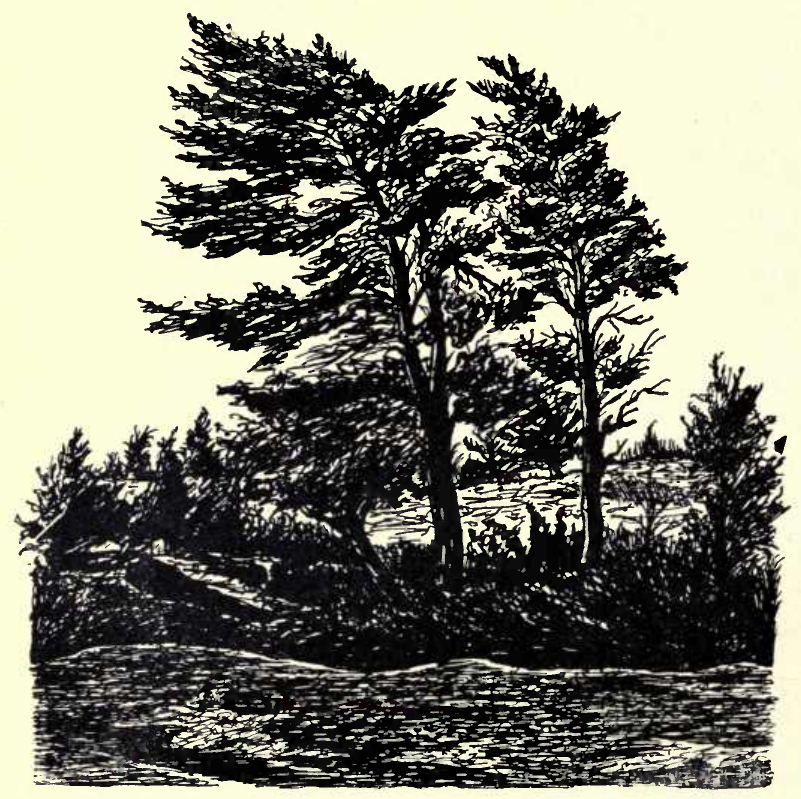


the average fish has an eye which can see more in a second than the ordinary human being would see in a week; the least appearance of deceit frightens it and brings it to a standstill; and the chance is that the angler who practises fraud will be outwitted by instinct and cunning. It is true that when fish are very plentiful and very hungry they will often take bait of any kind, especially if it be kept in motion; but generally they require a very tempting bait.

3. Any kind of woven line may be used, provided it is durable and not too coarse. Fine braided linen is the most economical, although it rots easily, if not carefully dried before reeling up.

Be sure to test your line, foot by foot, before you go on a fishing expedition. It only takes a few minutes, and will save you many an anxious moment.

Braided silk is the best line of all, but not easy to procure in a uniform state throughout. Oiled silk is apt to have weak spots, as the oil seems to rot in places.

All lines, after being in the water, should be dried, if possible in the sun and wind, before being reeled up. Nothing rots a line so soon as reeling it up tightly when wet and then allowing it to remain in that state for two or three days, especially if the air be hot and humid.

4. The choice of a rod and reel is generally regulated by sentiment and the length of one's purse.

The beginner should purchase a rod and reel every year, so that he may have something to talk about during the long winter evenings, and especially in the early spring, when he begins to think of the pleasures of angling, and fancies he hears in the dim distance the song of the mosquito and the black fly.

By the time he is an old man, he will then have a collection of fishing material that would satisfy the nost ambitious, or the most fastidious, angler. Each rod will have its own story; and, if he has, in the end, to revert to the 
days of his youth, and use, in his old age, a simple bamboo rod and a still simpler reel, he will at least have the satisfaction of knowing that he has been a patron of industry, and has encouraged the manufacture of everything that pertains to the pleasant art of angling.

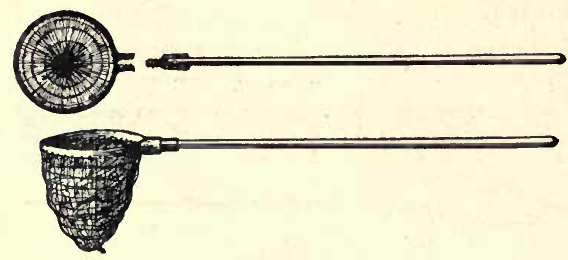

5. The landing-net is an indispensable aid to the angler. A solid brass ring with a jointed handle is the best. The ring may be circular or slightly pear-shaped, the latter being perhaps preferable.

Wooden rings are lighter, and therefore more easily manipulated. The meshes should be about one inch on the diagonal.

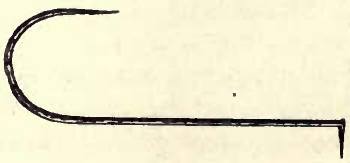

Gaff Hook

(One-half Natural Size)

6. For large fish such as pike or maskinonge, which weigh ten pounds or over, a gaff hook is a useful auxiliary.

7. For removing hooks that have been swallowed, a disgorger should be used; in its absence, a long lead pencil 
or rounded stick, with a slit across the flat end, may be employed.

8. The best all-round bait is the live minnow; the larger the minnow, the larger the fish one is likely to catch.

9. It is important sometimes to have a change of bait, especially when fish are not biting freely. Frogs, minnows, and worms make a good selection. If a fish has been hooked, and after being played some time, manages to escape, one
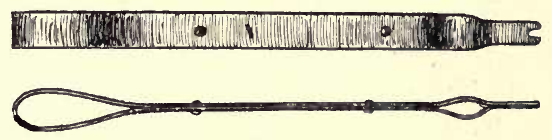

Disgorger

can very often entice him to bite again by using a change of bait.

10. Regarding weather proverbs, the best one to remember is that fish bite in all kinds of weather if they are hungry. I have caught bass, pike, perch, pickerel, and the smaller pan fish in sunshine and in rain, fair weather and foul, and I do not believe that weather conditions have much to do with angling.

For example, the old adage which states that fish will not bite in an east wind, is untrue; for why should the direction of the wind affect a fish's stomach? It is probable that fish are disturbed by slight barometric changes, and that they become restive in dull, cloudy weather, with a low barometer, and therefore move about more freely under such conditions; but, as far as nyy experience goes, the only thing which really seems to affect them is a violent thunderstorm, which apparently frightens them and drives them into deep water. I have tried, time and again, to catch fish during a rain storm, accompanied by thunder and lightning, but have never been successful. 
11. Concerning the theory that fish bite better at daybreak, I am not in a position to give much information. Only once was I induced by a barbarian to rise at $3 \mathrm{a} . \mathrm{m}$. to see the sun rise, and to go fishing; and my experience on that occasion leads me to believe that fish sleep in the early morning, and do not begin to feed before ten or eleven o'clock; at least, I prefer to believe that such is the case, and therefore advise all anglers to beware of the habit of early rising, which is just as demoralizing and as objectionable as that of intemperance in eating or drinking.

12. The boat, or punt, from which one fishes, should be painted dull lead or green, as nearly as possible the colour of the water; this is important on a bright day, although not so necessary in cloudy weather.

Fish are very easily frightened at times, and the approach of a boat with a white or varnished bottom will often scare them away.

Pure dry white lead, lamp-black, boiled linseed oil, and a small quantity of green paint, can be mixed to obtain the proper shade.

13. Sounds travel easily through water, so that the less noise one makes, when angling, especially in calm weather, the better the chance of catching fish.

14. In anchoring a boat, use an ordinary stone and a piece of clothes-line attached to the painter of the boat.

In rivers or lakes with mud bottom there is no difficulty in anchoring, and the stone or anchor may be easily lifted when one wishes to change his position; but, when the bottom is broken, very often the anchor becomes wedged between rocks, and there is no remedy but to cut the line. This is a common occurrence in rocky lakes, so that an angler should always be provided with a jack-knife, or he may find himself in a very uncomfortable position in rough weather.

15. Fish shoild be killed as soon as caught by breaking 
the neck; if thrown in the boat and allowed to die, their flavour is completely destroyed. Moreover, nothing gives a boat such a horrible odour as the slime from fish, so that a flat tray with a cover should be provided to hold them.

16. All fish should be scaled and cleaned as soon as possible; this is particularly true in the case of bass, both large and small-mouthed, rock bass, sunfish, and pike. Perch and pickerel will keep much longer, but then they must be skinned, which takes away a great deal of their flavour.

Catfish and eels are the only fish from which the skin should be removed.

17. It may be taken as a general law that all fish take bait or fly most readily just about sundown.

The End. 


UC SOUTHERN REGIONAL LIBRARY FACUTY

A $000028163 \quad 4$ 
